\title{
Effect of Co Doping on Magnetic and CO-SCR Properties of $\gamma-\mathrm{Fe}_{2} \mathrm{O}_{3}$
}

Xuemei Ou, Kean Chen, Longqing Wei, Yaqian Deng, Ju Li, Bin Li, * Lihui Dong *

School of Chemistry and Chemical Engineering, Guangxi University, Daxue East Road 100, Nanning 530004, P. R. China

E-mail address: binli@gxu.edu.cn; donglh@gxu.edu.cn

\section{Abstract:}

Magnetic bayberry-like $\gamma$-xCoFe $\mathrm{O}_{3}$ microspheres catalysts with different mole ratio $(\mathrm{Co} / \mathrm{Fe}=0,1,3,5,7,9 \%)$ are synthesized by solvothermal method followed by calcination. Then a series of characterizations are carried out, including Raman spectra, XRD, BET, $\mathrm{H}_{2}$-TPR, VMS, XPS and in situ DRIFTS spectra. And as the results indicate that with Co doping amount increasing, the microspheres shrink first and then expand, which obviously affect the specific surface area and activity, samples' catalytic performance are improved by doping appropriate amount of cobalt, and $5 \mathrm{Co}-\mathrm{Fe}$ has the optimum activity with the largest surface area. Moreover, In-situ DRIFTS result shows that the introduction of Co promotes the formation of decomposable monodentate nitrates rather than chelate bidentate nitrates and improve samples' magnetic properties, which promote more NO adsorbed on catalyst surface to form chelate nitrate species, so that enhanced the activity.

Keywords: Magnetic, Ferrite catalyst, $\gamma-\mathrm{xCoFe}_{2} \mathrm{O}_{3}, \mathrm{CO}-\mathrm{SCR}$

\section{Introduction}

Prior works have revealed that technical means and materials used for NO elimination are diversified. Many scholars in the field of environmental protection have conducted extensive research on NO elimination through numerous means, and achieved corresponding excellent results. Because the precious metals became more scarce and expensive, the researchers turned their attention from noble metal catalysts to rare earth elements and transition metal oxides and composite oxides with rich content, low price, excellent structure and function.(1-5) For instance, Bahrami, 
Soudabe and the co-authors studied the impact of the composite nanocatalysts $\mathrm{CeO}_{2}-\mathrm{MO}_{\mathrm{x}}(0.25)(\mathrm{M}=\mathrm{Cu}, \mathrm{Fe}$ and $\mathrm{Mn})$ to $\mathrm{NO}$ oxidation. Then got the conclusion that NO conversion obtained via experimental were almost identical with that predicted by ANN-GA system, both are about $90 \%$ at $300{ }^{\circ} \mathrm{C}$ (3). M.S. Fal Desai successfully prepared cobalt oxide spinel substituting precious metal nano catalysts by auxiliary citrate sol-gel method. And the order of activity follows as $\mathrm{Rh}_{0.05} \mathrm{Co}_{2.95} \mathrm{O}_{4}>$ $\mathrm{Pd}_{0.05} \mathrm{Co}_{2.95} \mathrm{O}_{4}>\mathrm{Ru}_{0.05} \mathrm{Co}_{2.95} \mathrm{O}_{4}$, which showed that doped metal was beneficial to the adsorption of $\mathrm{CO}$ and NO. Furthermore, activity and stability of the catalyst were improved.(6) Pegah Rezaei et al synthesized $\mathrm{M}-\mathrm{Fe}_{2} \mathrm{O}_{3}-\mathrm{CuO}$ (M: $\mathrm{Ag}, \mathrm{Mn}$ and $\mathrm{Co}$ ) nanocatalysts in a new ultrasonic auxiliary hydrothermal treatment methods. The results indicated that the low temperature catalytic effect of the catalyst with $10 \mathrm{wt} \%$ $\mathrm{Mn}$ in $\mathrm{Cu}-\mathrm{FeO}_{\mathrm{x}}$ is improved, also achieved $\mathrm{CO}$ full conversion at $100{ }^{\circ} \mathrm{C}$.(7) Yuting Bai investigated the catalytic performance of $\mathrm{CuO} / \mathrm{CeO}_{2}-\mathrm{Al}_{2} \mathrm{O}_{3}$ catalysts. The physicochemical properties of the catalyst were adjusted by changing $\mathrm{Ce} / \mathrm{Al}$ appropriately, which showed Ce was beneficial to improve the catalytic effect and $\mathrm{N}_{2}$ selectivity, also make the catalyst possess excellent resistance to $\mathrm{O}_{2}$ and $\mathrm{SO}_{2}(8)$.

Considering transition metals, there is an important property that cannot be ignored-magnetism, because of its magnetic response characteristics, magnetic materials are easy to self-assemble and recycle, which not only achieve magnetic separation of catalysts effectively and but also makes it possible to quickly promotes the activity of catalysts,(9-12). Due to the combination of catalytic properties and magnetism, it possible to enhance the catalytic active components. $(13,14)$ Among many transition metal oxides, iron ores such as $\left(\mathrm{FeO}, \mathrm{Fe}_{2} \mathrm{O}_{3}, \mathrm{Fe}_{3} \mathrm{O}_{4}\right)$ or iron-based composite oxides $\mathrm{MFe}_{2} \mathrm{O}_{4}(\mathrm{M}=\mathrm{Co}, \mathrm{Mn}, \mathrm{Cu}, \mathrm{Zn}, \mathrm{Fe}, \mathrm{Ni}, \mathrm{Mg}$ and the like) are the most common ferromagnetic materials $(15,16)$. In recent years, they have been widely used in the fields of environmental conservation, magnetothermal therapy and catalysis.(17-21) S narimani-sabeghet et al. established an efficient magnetic solid phase extraction method, they used maghemite $\left(\gamma-\mathrm{Fe}_{2} \mathrm{O}_{3}\right)$ nanoparticles as the effective adsorbent to measure the antimony in aqueous solution, which achieved the separation and enrichment of antimony rapidly and simply.(22) Fatemeh Kiani et al. prepared the 
$\mathrm{NiFe}_{2} \mathrm{O}_{4} @ \mathrm{SiO}_{2}$-BPMN-Ni magnetic nanoparticles which was a green, novel and efficient synthetic method to biphenyl derivatives.(23) N. Ansari and others reported a facile synthesis method for water stablized iron intercalated multilayer graphene nanocomposite, the material with high magnetic moments was used as superior water pollutant remediators.(24) This new nanocomposite shows highly effective remedial for cationic/anionic azo dyes, the prominent sorption capability of the material was the result of combined action of activated carbon and magnetic properties of iron.

Melissa Greta Galloni et al demonstrated a convenient but valid synthesis scheme for iron based core-shell magnetic nanoparticles used in wastewater treatment and heterogeneous catalysis. The results shown that the core-size and loading of Fe was controled by adjustment synthesis parameters, while the packaging process of the multi-layer material were irrelevance with the properties of the iron oxide in nucleus.(25) Meanwhile, the magnetic core-shell structure materials as a magnetic separable carrier can be utilized in the field of water purification and the like by composite or modification with other materials $(26,27)$.

$\mathrm{Fe}_{2} \mathrm{O}_{3}$ is the most stable phase among all iron oxides, in which $\gamma-\mathrm{Fe}_{2} \mathrm{O}_{3}$ is a magnetic substance with cubic or tetragonal structure. It has become the subject and interest of modern materials research due to its unique and fascinating magnetic, electrical and dielectric properties. $(18,28) \breve{S}$ Luby et al synthesized the chemical resistor of $\mathrm{Fe}_{2} \mathrm{O}_{3}$ nanoparticle bilayer based on Langmuir-Schaefer method and examined the sensitivity to acetone vapours.(29) Peng Wang reported that mesoporous $\gamma-\mathrm{Fe}_{2} \mathrm{O}_{3}$ had comparable $\mathrm{Cr}$ (VI) adsorption capacity compared to non-porous $\gamma-\mathrm{Fe}_{2} \mathrm{O}_{3}$. But under the same experimental conditions, when external magnetic field existed, it had a faster adsorption rate than non-porous $\gamma-\mathrm{Fe}_{2} \mathrm{O}_{3}$, and achieved magnetic recovery or reuse by changing the $\mathrm{pH}$ value.(30) Aseya Akbar reported the synthesis and characterization of Co-doped $\mathrm{Fe}_{2} \mathrm{O}_{3}$ thin films with the ratio $\mathrm{Co} / \mathrm{Fe}$ between $0 \%-10 \%$. Magnetic hysteresis loops at room-temperature showed that with the increase of doping concentration, the saturation magnetization increased with the maximum at $8 \%$, but the doping concentration increased to $10 \%$, the magnetism decreased, which might be the result of more Co atoms were dispersed 
at the grain boundaries.(31) Our group's research shows that magnetism can promote the adsorption and transform of NO molecules on magnetic substances. The magnetism of $\gamma-\mathrm{Fe}_{2} \mathrm{O}_{3}$ increases slightly after use in the reducing atmosphere, because when $\gamma-\mathrm{Fe}_{2} \mathrm{O}_{3}$ transcrystallization to $\mathrm{Fe}_{3} \mathrm{O}_{4}$, it will exhibit better stability, magnetism and catalytic properties.(32) These are just a few of the methods to synthesize and appliance $\gamma-\mathrm{Fe}_{2} \mathrm{O}_{3}$. Relatively speaking, $\mathrm{Fe}_{3} \mathrm{O}_{4}$ oxidation also has a good application prospect. $\mathrm{Fe}_{3} \mathrm{O}_{4}$, or $\mathrm{Fe}(\mathrm{III})[\mathrm{Fe}(\mathrm{II}) \mathrm{Fe}(\mathrm{III})] \mathrm{O}_{4}$, it's trans-spinel structure, and the morphology and crystal form are basically unchanged when it gradually weathered and oxidized to $\gamma-\mathrm{Fe}_{2} \mathrm{O}_{3}$.(31) As a result, the $\gamma-\mathrm{Fe}_{2} \mathrm{O}_{3}$ obtained after oxidation maintains the trans spinel structure. $(31,33,34)$ After $\mathrm{Fe}_{3} \mathrm{O}_{4}$ oxidated to $\gamma-\mathrm{Fe}_{2} \mathrm{O}_{3}, 1 / 3$ of $\mathrm{Fe}^{2+}$ move to the surface and oxidized, causing $5 / 6$ of these octahedral positions in its cell are occupied by $\mathrm{Fe}^{3+}$ and the rest about $1 / 6$ is cation vacancies on octahedrons (show in Figure 1). Because of the defects of the structure, it has greater potential use value.

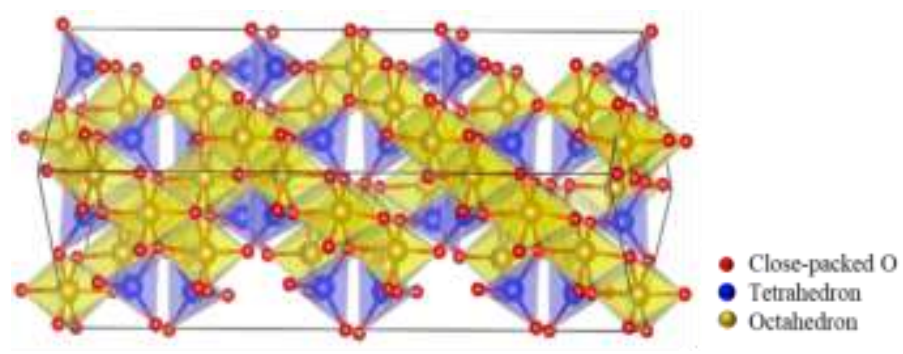

Figure $1 \gamma-\mathrm{Fe}_{2} \mathrm{O}_{3}$ cell units

Although there are many studies on the use of the series of catalysts in various fields and their corresponding mechanisms (35-38), but few explorations on the effect of the magnetic performance on the adsorption of active components and reactive molecules and the reaction mechanism, even less in the $\mathrm{DeNO}_{\mathrm{x}}$, one of $\mathrm{Fe}_{2} \mathrm{O}_{3}$ in many application fields.

Because of the directional arrangement of electrons in microscopic magnetic domains in magnetic field, and to ensure the uniformity of the magnetic self-assembled catalyst, spherical catalysts are the best choice for magnetic catalytic materials. Therefore, this experiment used synthetic $\mathrm{Fe}_{3} \mathrm{O}_{4}$ as intermediate oxidation to prepare $\gamma-\mathrm{Fe}_{2} \mathrm{O}_{3}$ to study the Co doping magnetic bayberry-like $\gamma-\mathrm{Fe}_{2} \mathrm{O}_{3}$ catalyst on 
CO-SCR. The catalysts also analyzed by various characterizations, such as BET, FESEM, HRTEM, XRD, VSM, $\mathrm{H}_{2}$-TPR and XPS. In the meantime, the optimal catalyst is tested by in situ DRIFTS spectra and then the possible mechanisms of NO $+\mathrm{CO}$ reaction is proposed.

\section{Experimental Section}

\subsection{Material}

$\mathrm{FeCl}_{3} \cdot 6 \mathrm{H}_{2} \mathrm{O}$, Co $\left(\mathrm{NO}_{3}\right)_{2} \cdot 6 \mathrm{H}_{2} \mathrm{O}$, sodium citrate, sodium acetate anhydrous, ethanediol, $\mathrm{C}_{2} \mathrm{H}_{6} \mathrm{O}$. All samples are analytical pure (99\%), purchased from Xilong Chemical Company Limited, and which were analytically pure used without further processing.

\subsection{Synthesis of $\gamma-\mathrm{xCoFe} \mathrm{O}_{3}$ catalyst}

Magnetic bayberry-like $\gamma$-xCoFe $\mathrm{O}_{3}$ are synthesized by modifying the method reported by Wei Jiang et al.(39) The schematic illustration for the synthesis and formation mechanism of $\gamma-\mathrm{Fe}_{2} \mathrm{O}_{3}$ magnetic microspheres show in (Figure. S1), and the specific steps are simplified as follows: $2.16 \mathrm{~g} \mathrm{FeCl}_{3} \cdot 6 \mathrm{H}_{2} \mathrm{O}, 4.8 \mathrm{~g}$ sodium acetate anhydrous, $0.5 \mathrm{~g}$ sodium citrate and cobalt nitrate $\left(\mathrm{Co}\left(\mathrm{NO}_{3}\right)_{2} \cdot 6 \mathrm{H}_{2} \mathrm{O}\right)(\mathrm{x}=0,1,3,5,7$, $9 \%)$ with corresponding different molar ratios $(\mathrm{Co} / \mathrm{Fe})$ are dissolved in $40 \mathrm{~mL}$ ethanediol. The solution was stirred vigorously until completely dissolved, and then transferred into $100 \mathrm{~mL}$ PTFE Teflon reactor, followed by sealed reaction at $200{ }^{\circ} \mathrm{C}$ for $20 \mathrm{~h}$. After cooling down to ambient temperature, the black solid products are magnetic separation and wash alternately with water and anhydrous ethanol several times, respectively. After vacuum drying at $60{ }^{\circ} \mathrm{C}$ for $4 \mathrm{~h}$, the intermediates are calcined at $300{ }^{\circ} \mathrm{C}$ for $2 \mathrm{~h}$ in air atmosphere to obtain $\gamma-\mathrm{xCoFe}{ }_{2} \mathrm{O}_{3}$. The products were named in turn as $\gamma-\mathrm{Fe}_{2} \mathrm{O}_{3}, 1 \mathrm{Co}-\mathrm{Fe}, 3 \mathrm{Co}-\mathrm{Fe}, 5 \mathrm{Co}-\mathrm{Fe}, 7 \mathrm{Co}-\mathrm{Fe}, 9 \mathrm{Co}-\mathrm{Fe}$.

In order to compare the impact of magnetism on catalytic performance and mechanism, the sample with the best catalytic activity is placed on the magnet for two weeks at room temperature to enhance the room temperature magnetic properties, and then the catalytic activity and infrared spectroscopy measured. The magnetization 
method is shown in the (Figure. S2). The samples before(BM) and after(AM) magnetization are named as 5Co-Fe-BM and 5Co-Fe-AM, respectively.

\subsection{Catalyst characterizations}

X-ray diffraction (XRD) and Raman spectra are used to characterize the composition and structure of $\gamma-\mathrm{xCoFe} \mathrm{O}_{3}$ catalysts; X-ray photoelectron spectroscopy (XPS) is used to ascertain the elements valence of the metal oxides; field emission scanning electron microscopy (FESEM) and high resolution transmission electron microscope (HRTEM) are used to characterize the microstructure and tis parameters; the reducibility of $\gamma-\mathrm{xCoFe} \mathrm{O}_{3}$ are tested by $\mathrm{H}_{2}$ temperature programmed reduction $\left(\mathrm{H}_{2}\right.$-TPR); Magnetic parameters of the catalysts are characterized by vibrating sample magnetometer (VSM); the possible reaction mechanism of the catalyst is studied by in situ diffuse reflectance infrared spectra (in situ DRIFTS) test in different atmospheres.

\subsection{Catalytic activity evaluation}

The Catalytic performance of $\gamma-\mathrm{xCoFe}_{2} \mathrm{O}_{3}$ for $\mathrm{CO}-\mathrm{SCR}$ reaction are tested through the gas chromatograph(GC-9860) with fixed-bed reactor. There are about 25 mg screened samples (60 mesh) placed in the middle of glass tube, and ventilation with $\mathrm{N}_{2}$ pretreatment $1 \mathrm{~h}$ under $110{ }^{\circ} \mathrm{C}$ to blow away impurities. Droped to normal temperature after pretreated, the reaction gas consists by 5 vol\% of NO and $10 \mathrm{vol} \%$ of $\mathrm{CO}$ (both with $\mathrm{He}$ as equilibrium gas) accessed to adsorption $30 \mathrm{~min}$, with the flow rate of the mixed reaction gas through the quartz tube maintains around $31000 \mathrm{~mL} /(\mathrm{gh})$ (GHSV). Then the data are collected when the corresponding temperature reaches a steady state during heating. Catalytic performance evaluation is calculated through the following formulas:

$$
\begin{aligned}
& \mathrm{NO} \text { (conversion) }_{(\%)} \frac{\left([\mathrm{NO}]_{\text {in }}-[\mathrm{NO}]\right.}{[\mathrm{NO}]_{\mathrm{i}}} \times 100 \% \\
& \mathrm{~N}_{2 \text { (selectivity) }}(\%)=\frac{2\left[\mathrm{~N}_{2}\right]_{\text {out }}}{\left([\mathrm{NO}]_{\text {in }}-[\mathrm{NO}]_{\text {out }}\right)} \times 100 \% \\
& \mathrm{~N}_{2 \text { (yield) }}(\%)=\mathrm{N}_{2 \text { (selectivity) }} \times \mathrm{NO} \text { (conversion) }
\end{aligned}
$$




$$
\mathrm{CO} \text { (conversion) }(\%)=\frac{\left.[\mathrm{CO}]_{\text {in }}-[\mathrm{CO}]_{\text {out }}\right)}{[\mathrm{CO}]_{\text {in }}} \times 100 \%
$$

\section{Results and discussion}

\subsection{Catalytic activity}

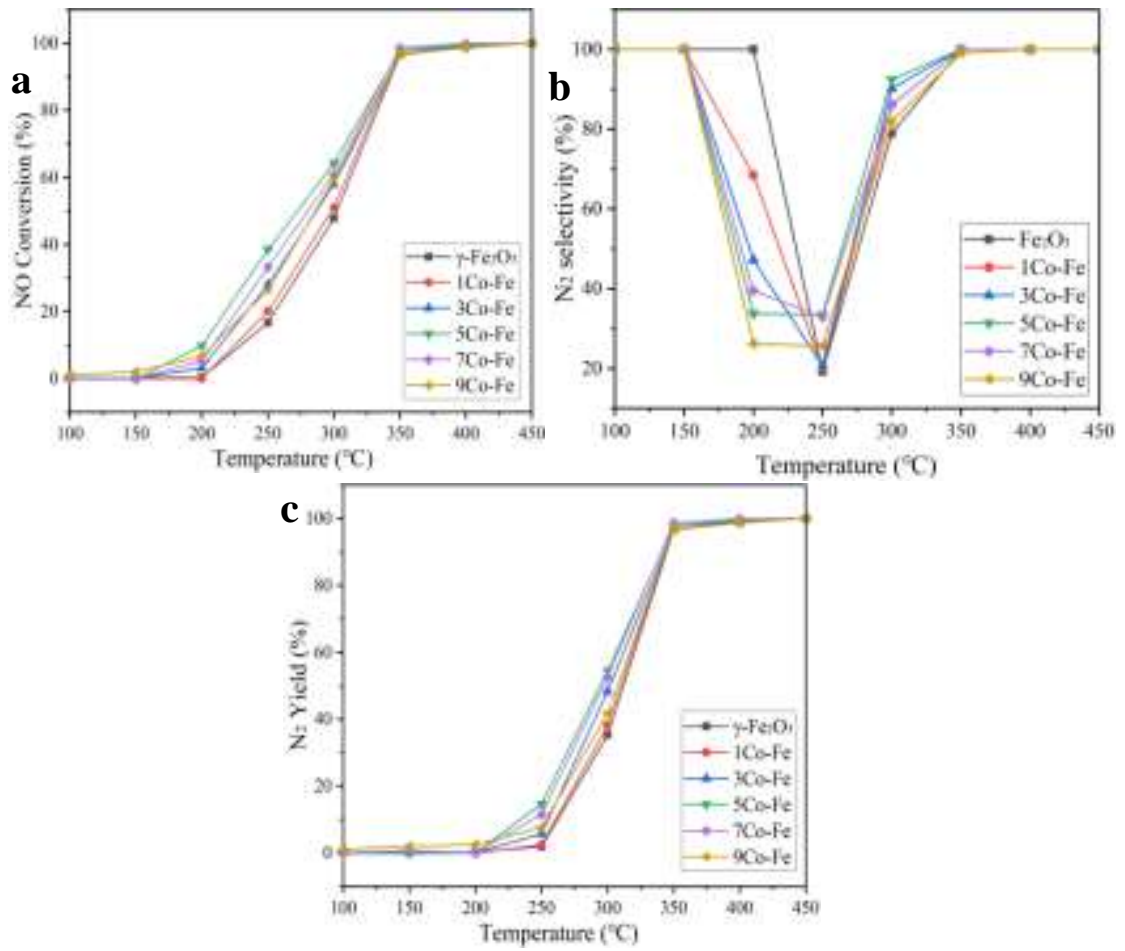

Figure 2. (a) $\mathrm{NO}$ conversion of $\gamma-\mathrm{xCoFe}_{2} \mathrm{O}_{3}$, (b) $\mathrm{N}_{2}$ selectivity of $\gamma-\mathrm{xCoFe}_{2} \mathrm{O}_{3}$ and (c) yield of $\mathrm{N}_{2}$ of $\gamma-\mathrm{xCoFe} \mathrm{O}_{3}$ at respective reaction temperatures;
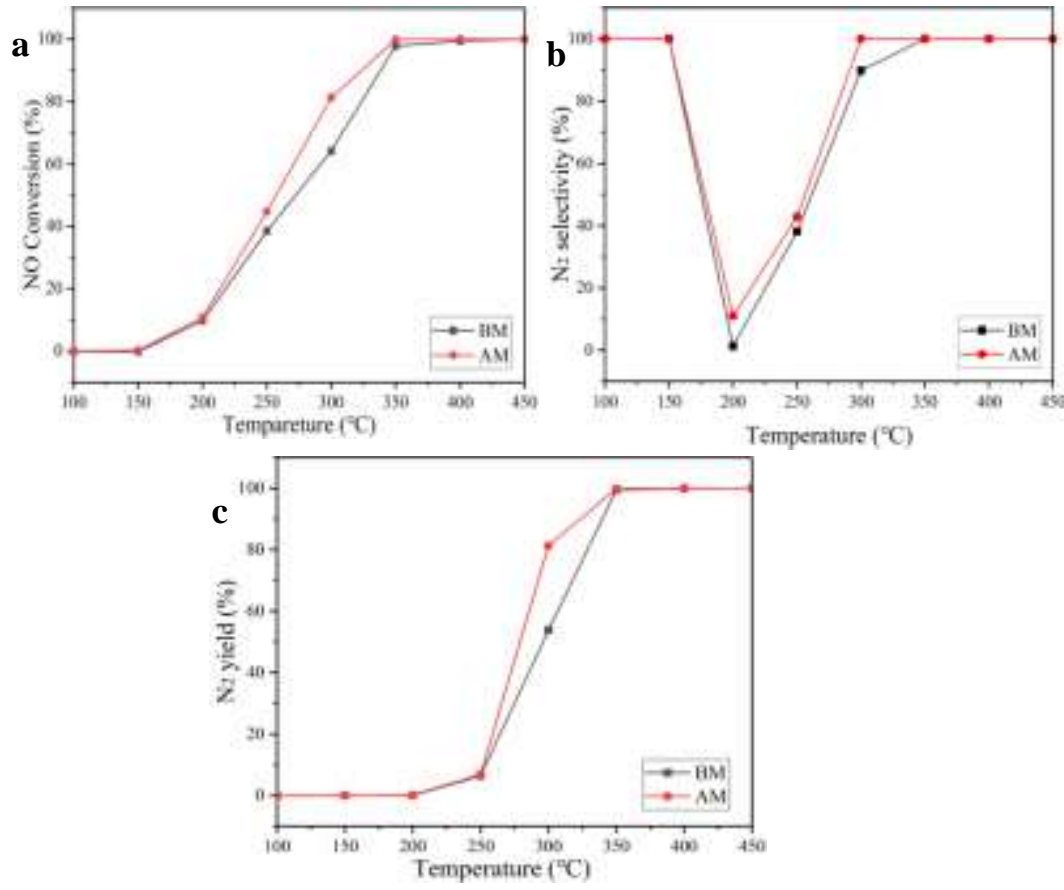
Figure 3. (a) NO conversion, (b) $\mathrm{N}_{2}$ selectivity and (c) yield of $\mathrm{N}_{2}$ of $5 \mathrm{Co}-\mathrm{Fe}$ sample before (BM) and after (AM) magnetization

Catalytic performance index, the NO conversion, $\mathrm{N}_{2}$ yield and $\mathrm{N}_{2}$ selectivity over a series of catalysts in the range of 30 to $450{ }^{\circ} \mathrm{C}$ are shown in Figure. 2. Figure. 2(a-c) show that with the increase of Co doping amount, the change of NO conversion, yield of $\mathrm{N}_{2}$ and $\mathrm{N}_{2}$ selectivity have the same trend, respectively. And the activities of all catalysts are extremely weak before $200{ }^{\circ} \mathrm{C}$, but increase significantly after $200{ }^{\circ} \mathrm{C}$ and reached $100 \%$ at $350{ }^{\circ} \mathrm{C}$. And the $5 \mathrm{Co}-\mathrm{Fe}$ is the optimal catalyst with best catalytic performance. It agreed with previously reported, the catalytic properties of iron oxide at low temperatures $\left(<250{ }^{\circ} \mathrm{C}\right)$ are not ideal. $(32,40)$ Figure. 3 shows the difference of catalytic performance of $5 \mathrm{Co}-\mathrm{Fe}-\mathrm{BM}$ and $5 \mathrm{Co}-\mathrm{Fe}-\mathrm{BM}$. It can be seen that $5 \mathrm{Co}-\mathrm{Fe}-\mathrm{AM}$ exhibits better catalytic properties, and magnetism can promote NO conversion. In order to further explore the causes of catalytic performance differences, here following some characterizations for these samples and the results show below.

\subsection{Phase and structure results of the catalysts}
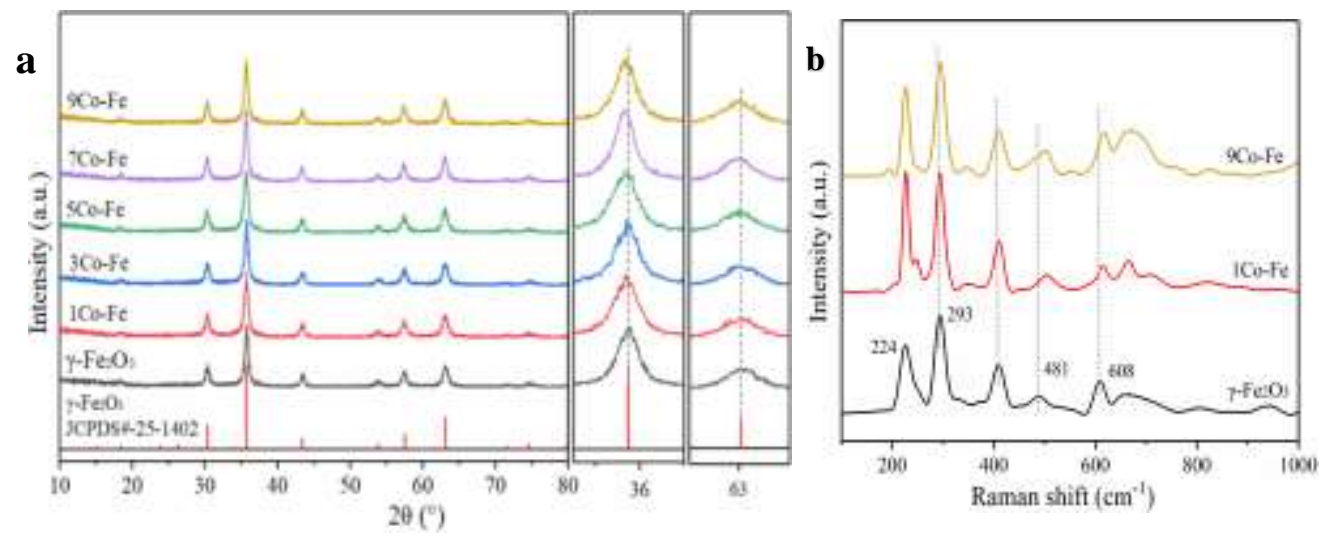

Figure 4. (a) XRD image and (b) Raman spectra of $\gamma-\mathrm{xCoFe}_{2} \mathrm{O}_{3}$

As Figure. 4(a) depicts is the XRD patterns of the $\gamma-\mathrm{xCoFe}_{2} \mathrm{O}_{3}$ samples. Pure $\mathrm{Fe}_{2} \mathrm{O}_{3}$ displays all clear diffraction peaks completely corresponding to maghemite structure, with the standard card (JCPDS NO.25-1402).(41) As a result, the phase of $\gamma-\mathrm{Fe}_{2} \mathrm{O}_{3}$ magnetic micro-nanoparticles is face-centered cubic structure (Figure 1). Set $\gamma-\mathrm{Fe}_{2} \mathrm{O}_{3}$ as a reference, all samples' diffraction peaks are consistent with $\gamma-\mathrm{Fe}_{2} \mathrm{O}_{3}$ and no peaks of cobalt oxide and other impurity are found.(42) From the enlarged picture, compared with pure $\gamma-\mathrm{Fe}_{2} \mathrm{O}_{3}$, before 5\% doping, the shift of the peak of the (119) 
crystal plane at $35.7^{\circ}$ is almost slight, but when it continues to increase to $7 \%$, we can see obviously low angle offset marks. With less $\mathrm{Co}$ doping, $\mathrm{Co}^{2+}$ distribute on surfaces or grain boundaries randomly, when the doping content increases to a certain threshold, $\mathrm{Co}^{2+}$ will occupy a certain octahedral gap in the $\gamma-\mathrm{Fe}_{2} \mathrm{O}_{3}$ cell to occupy a certain cation vacancy to maintain its trans spinel structure. The bulk (ICP-AES) compositions of samples are shown in table 1 , the actual value of $\mathrm{Co} / \mathrm{Fe}$ ratio less than theoretical one, indicating Co loss during sample preparation. But with more Co, it's possible to form $\mathrm{CoFe}_{2} \mathrm{O}_{4} \cdot(43)$

Simultaneously, because the extremely similarity of the XRD of spinel structure oxide, the structure of bayberry-like $\gamma-\mathrm{xCoFe}_{2} \mathrm{O}_{3}$ samples are further investigated by Raman spectra. As exhibited in Figure. 3(b), there are five bands situated at 214, 274, 381,500 and $586 \mathrm{~cm}^{-1}$ belong to maghemite $\gamma-\mathrm{Fe}_{2} \mathrm{O}_{3}$. (41) After careful comparison, it can be found that the existence of the Co caused the high wavenumber migration of the marked peak position, this is due to the lattice distortion caused by the Co ions incorporated into the $\gamma-\mathrm{Fe}_{2} \mathrm{O}_{3} \cdot(40,44,45)$

\subsection{XPS and HRTEM results}
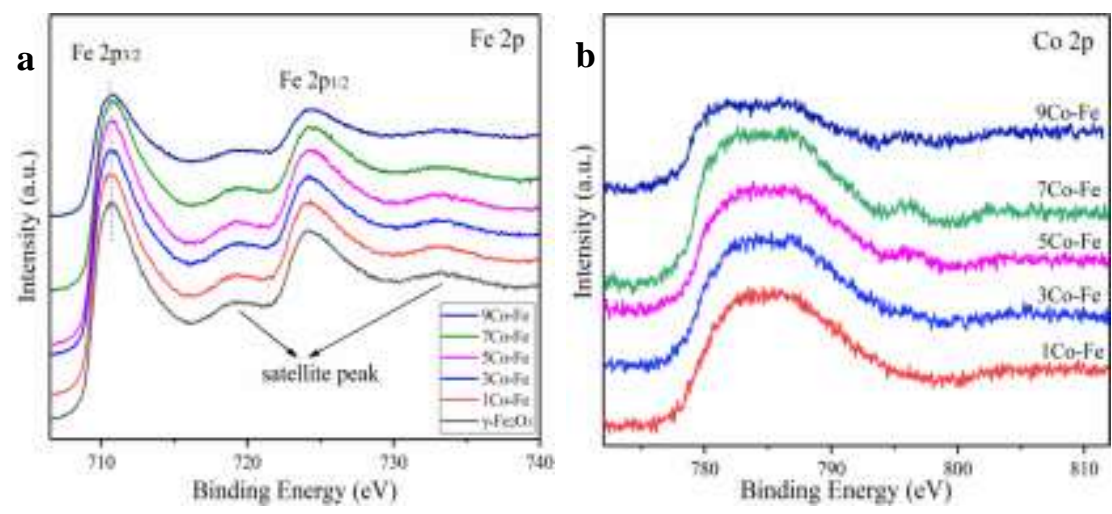


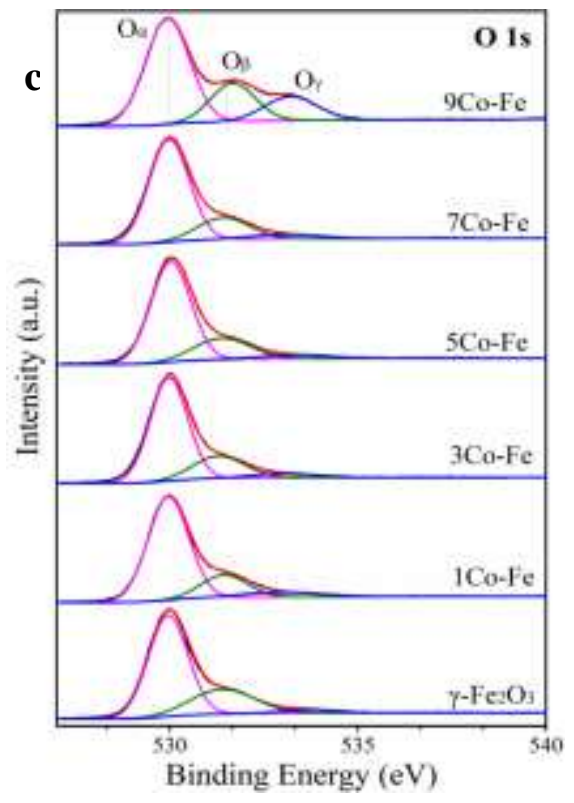

Figure 5. the XPS spectras: (a) Fe 2p of $\gamma-\mathrm{xCoFe}_{2} \mathrm{O}_{3}$, (b) Co 2p of 1-9Co-Fe and (c) $\mathrm{O} 1 \mathrm{~s}$ of $\gamma-\mathrm{xCoFe} \mathrm{O}_{3}$

Figure. (5) are the XPS spectras of $\gamma-\mathrm{xCoFe}_{2} \mathrm{O}_{3}$ products. Figure. 5(a) is the $\mathrm{Fe}$ $2 \mathrm{p}$ spectra of all catalysts, in which we can observed two obvious characteristic peaks of $\mathrm{Fe} 2 \mathrm{p}_{3 / 2}$ and $\mathrm{Fe} 2 \mathrm{p}_{1 / 2}$ at 710.6 and $724.4 \mathrm{eV}$, and the separation of $\mathrm{Fe} 2 \mathrm{p}$ doublet is about $14.0 \mathrm{eV}$; the two satellite peaks also can be observed, they located at 719 and $733.5 \mathrm{eV}$, respectively, all samples show the same spectral shape, in which the iron species basically exist in a $\mathrm{Fe}^{3+}$ state. $(46,47)$ This is highly consistent with the results of the XRD (Figure. 4(a)), which indicates all samples are $\gamma-\mathrm{Fe}_{2} \mathrm{O}_{3}$ spinel-structure. The characteristic peak shown in Figure. 5(b) is assigned to the Co $2 p$, two peaks located at 780.8 and $796.1 \mathrm{eV}$, which can be attributed to Co $2 \mathrm{p}_{3 / 2}$ and Co $2 \mathrm{p}_{1 / 2}$, respectively. And the difference of binding energy of the two peaks is approximately $15.6 \mathrm{eV}$, which is the characteristic of $\mathrm{Co}^{2+}$, confirming the oxidation state of $\mathrm{Co}^{2+}$ in $\gamma$-xCoFe ${ }_{2} \mathrm{O}_{3}$, consistent with the reports. $(43,47)$ After careful observation and comparison of Figure. 5(a), it is not difficult to see that With the increase of Co-doping amount, the $\mathrm{Fe} 2 \mathrm{p}_{3 / 2}$ peak of the catalyst shifts to the high binding energy sightly, due to the difference in electronegativity, some of the electrons are biased from $\mathrm{Fe}(1.83)$ to more negative $\mathrm{Co}(1.88),(40)$ and that suggests that there is a synergy between Co-Fe. XPS results further confirm the conclusion that $\mathrm{Co}$ ions are in the form of $\mathrm{Co}^{2+}$ and successfully enter the $\gamma-\mathrm{xCoFe}_{2} \mathrm{O}_{3}$ cell. 
From the O1s spectra Figure. 5(c), the O 1s spectra can be deconvoluted into three peaks $\left(\mathrm{O}_{\alpha}, \mathrm{O}_{\beta}, \mathrm{O}_{\gamma}\right)$. At $530 \mathrm{eV}\left(\mathrm{O}_{\alpha}\right)$, the main band is formed, which is the lattice oxygen $\left(\mathrm{O}^{2-}\right)$ bound to metal cations. The shoulder peak at $531.2 \mathrm{eV}\left(\mathrm{O}_{\beta}\right)$ is treated as chemisorbed oxygen $\left(\mathrm{O}^{-}, \mathrm{O}_{2}{ }^{2-}\right)$ and the last peak at $533.8 \mathrm{eV}$ generally assigned to the hydroxyl oxygen on surface $\left(\mathrm{O}_{\gamma}\right) \cdot(21,48)$ It is generally believed the surface adsorbed oxygen $\left(\mathrm{O}_{\beta}\right)$ is easier to move and participate in the reaction than lattice oxygen $\mathrm{O}_{\alpha}$, which promotes the catalytic process of NO and CO reaction. The XPS results further confirm the conclusion that $\mathrm{Co}$ ions enter the $\mathrm{Fe}_{2} \mathrm{O}_{3}$ cell in the form of $\mathrm{Co}^{2+}$ and form $\gamma$-xCoFe ${ }_{2} \mathrm{O}_{3}$. Generally, higher $\mathrm{O}_{\beta} / \mathrm{O}_{(\alpha+\beta+\gamma)}$ values imply more reactive oxygen species on the surface, so that which boosts the redox process.(32) When less Co doping, the results are consistent with previous conclusions, but here, with more Co doping it's possible to form $\mathrm{CoFe}_{2} \mathrm{O}_{4},(40)$ although the $\mathrm{O}_{\beta}$ has increased, its catalytic performance is inferior to that of other samples. According to the XPS spectra in table 1, all samples have similar $\mathrm{O}_{\beta} / \mathrm{O}_{(\alpha+\beta+\gamma)}$ values, obviously, the surface adsorbed oxygen is not the main factor affecting catalytic activity.

Table 1. XPS surface oxygen content of $\gamma-\mathrm{xCoFe}_{2} \mathrm{O}_{3}$

\begin{tabular}{|c|c|c|c|c|c|}
\hline & \multicolumn{3}{|c|}{ XPS results } & \multirow[t]{2}{*}{ ICP results } & \multirow[t]{2}{*}{ Theoretica } \\
\hline & \multicolumn{3}{|c|}{ Surface O } & & \\
\hline Samples & $\begin{array}{c}\mathrm{O}_{\alpha} / \mathrm{O}_{(\alpha+\beta+\gamma)} \\
(\%)\end{array}$ & $\begin{array}{c}\mathrm{O}_{\beta} / \mathrm{O}_{(\alpha+\beta+\gamma)} \\
(\%)\end{array}$ & $\begin{array}{c}\mathrm{O}_{\gamma} / \mathrm{O}_{(\alpha+\beta+\gamma)} \\
(\%)\end{array}$ & $\mathrm{Co} / \mathrm{Fe}(\%)$ & $\mathrm{Co} / \mathrm{Fe}(\%)$ \\
\hline$\gamma-\mathrm{Fe}_{2} \mathrm{O}_{3}$ & 69.7 & 27.3 & 3 & 0 & 0 \\
\hline $1 \mathrm{Co}-\mathrm{Fe}$ & 75.22 & 18.6 & 6.18 & 0.81 & 1 \\
\hline $3 \mathrm{Co}-\mathrm{Fe}$ & 73.35 & 21.71 & 4.94 & 2.26 & 3 \\
\hline $5 \mathrm{Co}-\mathrm{Fe}$ & 73.57 & 21.81 & 4.62 & 3.86 & 5 \\
\hline 7Co-Fe & 74.53 & 20.24 & 5.23 & 5.47 & 7 \\
\hline 9Co-Fe & 61.18 & 23.28 & 15.54 & 6.82 & 9 \\
\hline
\end{tabular}

\subsection{Morphological and structure analysis}



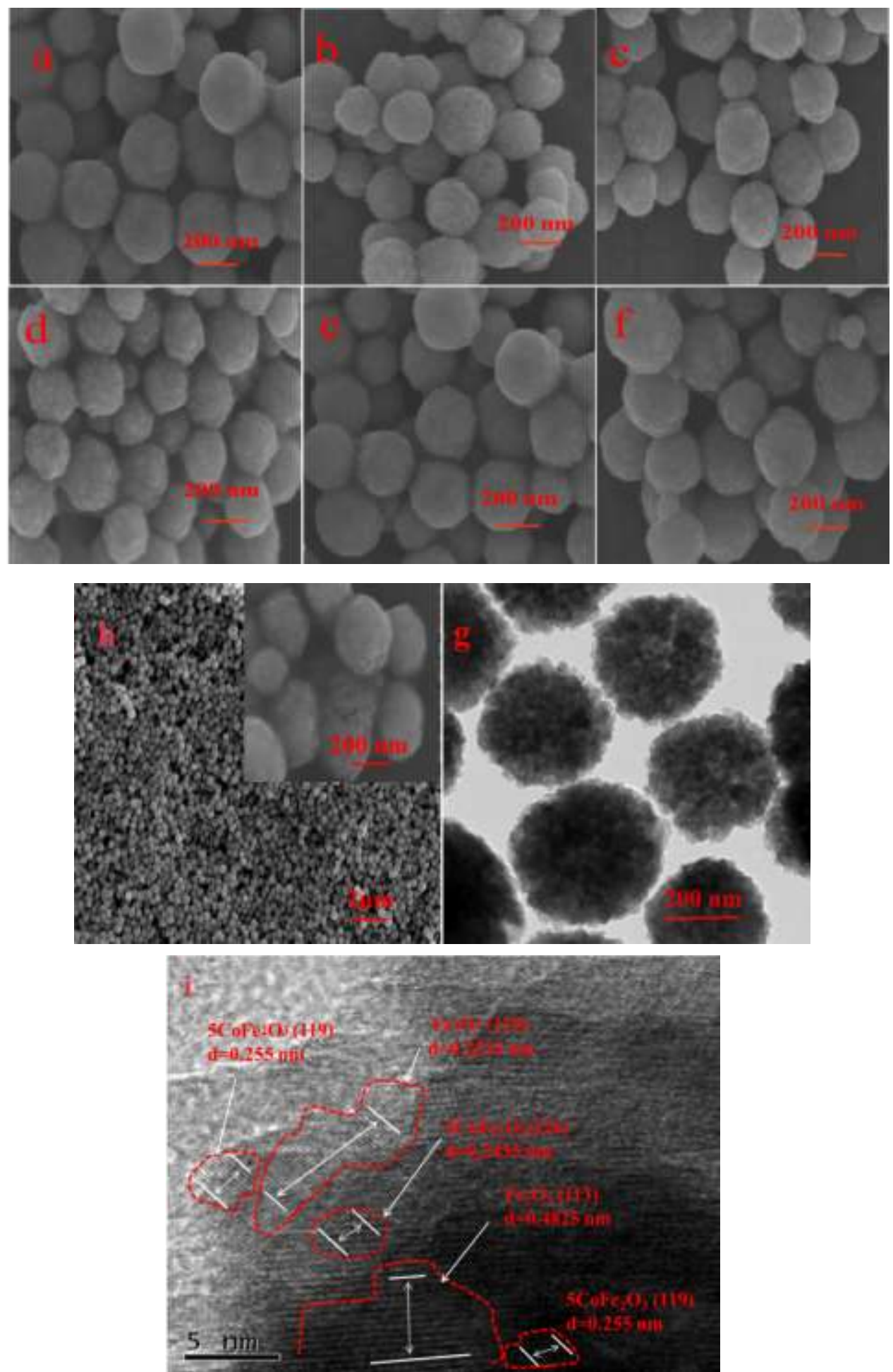

Figure 6. (a-f) SEM images of $\gamma-\mathrm{Fe}_{2} \mathrm{O}_{3}$ and 1-9Co-Fe, (h) low and high magnification images, (g-i) FESEM and HRTEM images of optimal catalyst 5Co-Fe, respectively

The morphological and sizes results of the obtained $\gamma-\mathrm{CoFe}_{2} \mathrm{O}_{3}$ samples are further investigated through (FESEM) and (HRTEM). From FESEM images in Figure. 6(a-f) and the HRTEM images in Figure. 6(g-i), it can be found that the as-synthesized bayberry-like micro/nano nanoparticles well formed with a relatively 
uniform spherical shape, and that most of these nanoparticles are distributed in the range of 200-300 $\mathrm{nm}(39)$, and the Figure. 6(h) confirms the uniform properties of the morphology. From the embedded graph, it is not difficult to find that these large-particle nanospheres are composed of smaller particles, which are the results of the combination of surface energy minimization and magnetic anisotropy, and it's consistent with previous reports.(49) But at room temperature, the magnetic material is difficult to assemble into compact single-crystal structure, so that obtained the products with bayberry-like mesoporous structure.(49) According to its oxidation process, calcination didn't change its morphology and crystal form(50). Therefore, $\gamma-\mathrm{Fe}_{2} \mathrm{O}_{3}$ still belongs to a trans spinel structure, which has the same bayberry-shaped large particles with small particle size as the intermediate $\mathrm{Fe}_{3} \mathrm{O}_{4}$. And it seems that the introduction of Co does not cause obvious changes in morphology. But after careful observation and comparison, it was found that with the increase of Co doping, sizes of bayberry-like microspheres decreased firstly and then increased, and the particle size of $5 \mathrm{Co}-\mathrm{Fe}$ is relatively small and uniform. In order to further ascertain the morphology change of $\gamma-\mathrm{CoFe}_{2} \mathrm{O}_{3}$ catalysts, the particle size of smaller iron oxide granules on these bayberry-like microspheres can be calculated according to the sample XRD patterns and the following Debye--scherrer equation(31) as shown:

$$
\mathrm{D}=\frac{0.89 \lambda}{\beta \cos \theta}
$$

in which $\mathrm{D}$ is the average crystallite size, $\lambda$ is the wavelength of the incident X-ray beam $(1.540 \AA)$; $\theta$ is the Bragg diffraction angle and $\beta$ is the peak width at half width maximum (FWHM). As shown in table 2, the average crystallite sizes of $\gamma-\mathrm{CoFe}_{2} \mathrm{O}_{3}$ samples are in the range 11-13 nm(39) and the detail results are presented in Table 2.

In the FESEM (Figure. 6(g)), it shows that these large bayberry-like microspheres are made up of smaller particles, which is consistent with the previous view and confirms the existence of pore channels in the catalyst, which consistent with the previous view $(39,49)$. The lattice fringes of $\gamma-\mathrm{Fe}_{2} \mathrm{O}_{3}$ (113), (119) are about 0.4825 and $0.2515 \mathrm{~nm}$ as shown in Figure. 5(i). And the lattice fringes of 
(226) and (119) crystallographic plane of 5Co-Fe expand to 0.2435 and $0.255 \mathrm{~nm}$, that's consistent with XRD and further confirms that Co enter into $\gamma-\mathrm{Fe}_{2} \mathrm{O}_{3}$ cell in the catalyst. EDS element Map of 5Co-Fe samples shows in Figure. 7, which clearly shows that $\mathrm{Co}, \mathrm{Fe}, \mathrm{O}$ are highly evenly dispersed state on the microspheres.

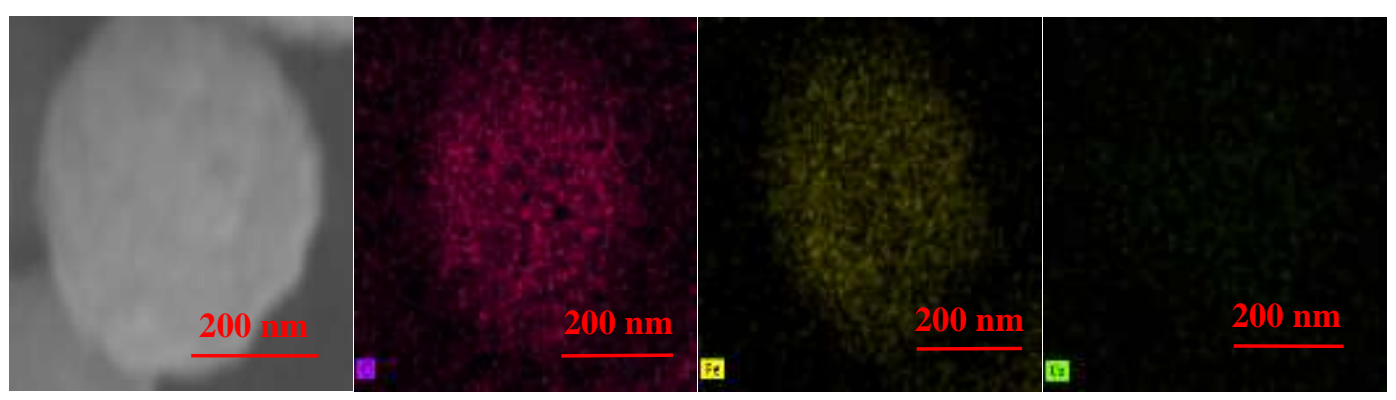

Figure 7. EDS element-mapping images of $\mathrm{O}$ (red), $\mathrm{Fe}$ (yellow), and $\mathrm{Co}$ (green) in

$5 \mathrm{Co}-\mathrm{Fe}$ catalyst

\subsection{Structural characterization (BET)}

Figure. 8 shows the texture characteristics of the prepared catalysts characterized and tested through $\mathrm{N}_{2}$ adsorption-desorption isotherm and aperture size distribution. As shown in Figure. 8(a), all samples have typical similar IV characteristic isotherms, and obvious $\mathrm{H}_{3}$ hysteresis loop (IUPAC classification) within the relative pressure (p/p0) range of 0.4-1, indicating that they have mesoporous structure characteristics. $(14,30,51)$ At the same time, it can be further determined from the aperture distribution in Figure. 8(b) that the aperture size distribution and pore sizes of all samples are in the range of 3.5-4 nm.(44)

The corresponding structure characteristics are summed in the table 2 . It can be seen that with the increase of Co content, the pore volume and specific surface area increase first and then decrease, while the pore size has the opposite trend. When the cobalt ions occupy $\gamma-\mathrm{Fe}_{2} \mathrm{O}_{3}$ certain cation vacancies, the growth of $\gamma-\mathrm{Fe}_{2} \mathrm{O}_{3}$ grains is inhibited, and thus a larger specific surface area to expose more active sites is obtained. Co addition also enhances the magnetic properties and mutual attraction of iron-based particles, which is the main reason for the decrease of particle size. Combined with BET data show in table 2, we know that $5 \mathrm{Co}-\mathrm{Fe}$ has the largest specific surface area but the smallest particle size. It can be seen that changes in these small particles lead to changes in specific surface area, which make 
bayberry-like micronanoparticles with high specific surface area and larger pore volume.(52) The larger specific surface area makes more active sites are exposed and leads better the catalytic effect, which is consistent with the previous reports(52).
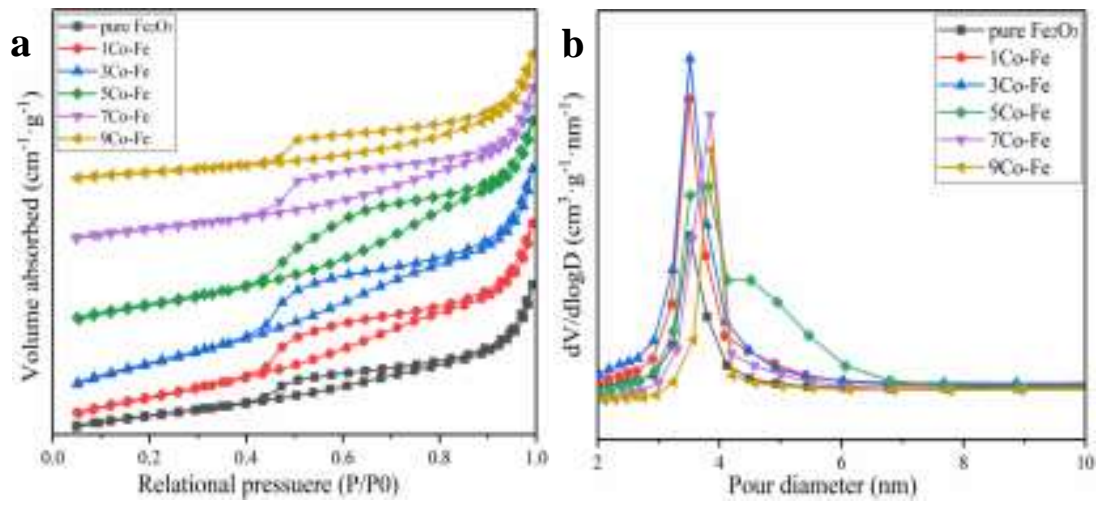

Figure 8. the results of (a) $\mathrm{N}_{2}$ adsorption-desorption isotherms and (b) aperture size distribution of $\gamma-\mathrm{xCoFe}{ }_{2} \mathrm{O}_{3}$

Table 2. The surface area and aperture structure parameters of $\gamma-\mathrm{xCoFe}_{2} \mathrm{O}_{3}$

\begin{tabular}{ccccc}
\hline catalysts & $\begin{array}{c}\text { BET surface area } \\
\left(\mathrm{m}^{2} / \mathrm{g}\right)\end{array}$ & $\begin{array}{c}\text { Pore volume } \\
\left(\mathrm{cm}^{3} / \mathrm{g}\right)\end{array}$ & $\begin{array}{c}\text { Pore size } \\
(\mathrm{nm})\end{array}$ & $\begin{array}{c}\text { Particle size } \\
(\mathrm{nm})\end{array}$ \\
\hline$\gamma-\mathrm{Fe}_{2} \mathrm{O}_{3}$ & 29 & 0.053 & 7.274 & 12.83 \\
$1 \mathrm{Co}-\mathrm{Fe}$ & 45 & 0.074 & 6.530 & 11.92 \\
$3 \mathrm{Co}-\mathrm{Fe}$ & 48 & 0.084 & 6.633 & 11.54 \\
$5 \mathrm{Co}-\mathrm{Fe}$ & 57 & 0.086 & 5.989 & 11.06 \\
$7 \mathrm{Co}-\mathrm{Fe}$ & 33 & 0.064 & 7.555 & 11.98 \\
$9 \mathrm{Co}-\mathrm{Fe}$ & 20 & 0.046 & 8.956 & 12.40 \\
\hline
\end{tabular}

\section{6 $\mathrm{H}_{2}$-TPR analysis of catalysts}




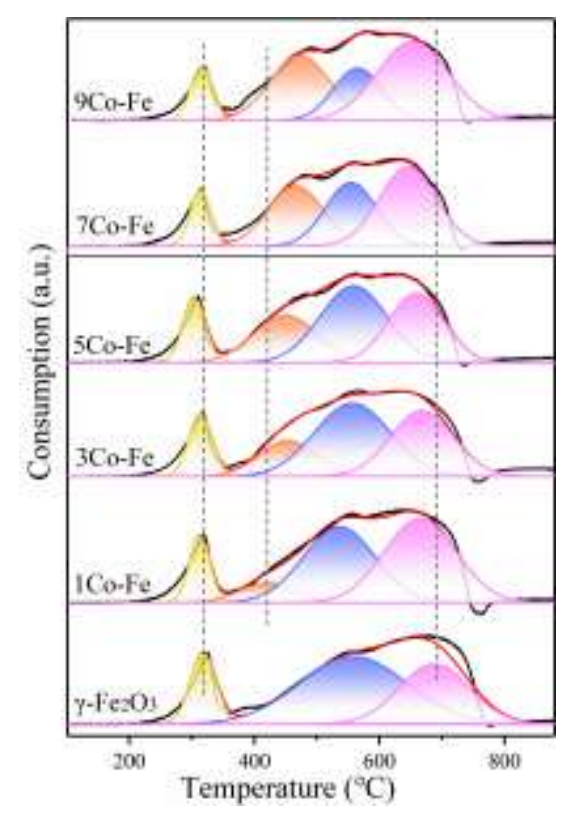

Figure 9. $\mathrm{H}_{2}$-TPR of $\gamma$-xCoFe $\mathrm{O}_{3}$ catalysts

Figure 9. shows the reducibility of $\gamma-\mathrm{xCoFe}_{2} \mathrm{O}_{3}$ catalysts, which is discussed by $\mathrm{H}_{2}$-TPR test between $100-900{ }^{\circ} \mathrm{C}$. And the reduction peaks of $\mathrm{Fe}_{2} \mathrm{O}_{3}$ are located at 320,560 and $650{ }^{\circ} \mathrm{C}$, which can be attributed to three-step reduction process of pure $\mathrm{Fe}_{2} \mathrm{O}_{3}, \mathrm{Fe}_{2} \mathrm{O}_{3} \rightarrow \mathrm{Fe}_{3} \mathrm{O}_{4}, \mathrm{Fe}_{3} \mathrm{O}_{4} \rightarrow \mathrm{FeO}$ and $\mathrm{FeO} \rightarrow \mathrm{Fe}$, respectively.(32,40,53) With the addition of Co content introduced into samples, the reduction temperature of the surface $\mathrm{Fe}_{2} \mathrm{O}_{3} \rightarrow \mathrm{Fe}_{3} \mathrm{O}_{4}$, slight moves to low temperature first and then increases. This is because when doping amount less than $5 \%$, which not only ensure the existence of a certain amount of oxygen vacancies, but also slightly enhance the synergy between Co-Fe and improve the reduction performance. $(21,40)$ When the Co content continues to increase, it will occupy more oxygen vacancies in octahedron. Meanwhile, the rapid electron transfer between the neighbor ions of $\mathrm{Fe}^{2+} / \mathrm{Co}^{2+}$ and $\mathrm{Fe}^{3+}$ in octahedron also increases the reduction temperature of $\mathrm{Fe}_{2} \mathrm{O}_{3} \rightarrow \mathrm{Fe}_{3} \mathrm{O}_{4}$. (54) What's more, in the range $470-520^{\circ} \mathrm{C}$, there is an enhanced peak with the increase of Co content, that is, cobalt reduction peak $\left(\mathrm{Co}^{2+} \rightarrow \mathrm{Co}^{0}\right)$.(55) These changes indicate that the $5 \mathrm{Co}-\mathrm{Fe}$ catalyst has best reduction ability and explained the reason why the 5Co-Fe exhibited optimal catalytic activity.

\subsection{VSM results}




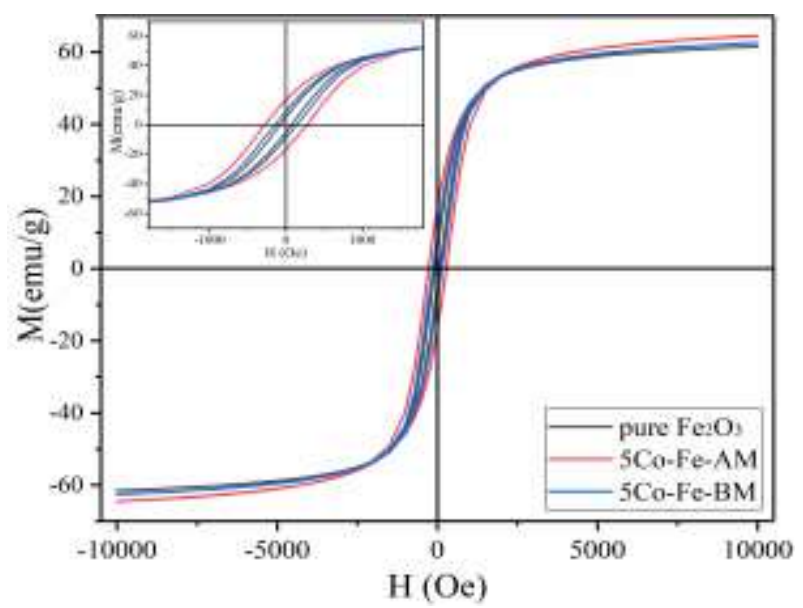

Figure 10. Samples' room temperature magnetization curves: pure $\gamma-\mathrm{Fe}_{2} \mathrm{O}_{3}$ (black), $\mathrm{BM}$ (blue) and $\mathrm{AM}$ (red) of the best active $5 \mathrm{Co}-\mathrm{Fe}$, respectively

Table 3. Comparison of magnetic parameters of pure $\gamma-\mathrm{Fe}_{2} \mathrm{O}_{3}$ and $5 \mathrm{Co}-\mathrm{Fe}$ before and after magnetization

\begin{tabular}{cccc}
\hline Samples & $\mathrm{Ms}(\mathrm{emu} / \mathrm{g})$ & $\mathrm{Mr}(\mathrm{emu} / \mathrm{g})$ & $\mathrm{Hc}(\mathrm{Oe})$ \\
\hline Pure $\gamma-\mathrm{Fe}_{2} \mathrm{O}_{3}$ & 61.52 & 5.14 & 80.3 \\
$5 \mathrm{Co}-\mathrm{Fe}-\mathrm{BM}$ & 62.56 & 9.06 & 140.2 \\
$5 \mathrm{Co}-\mathrm{Fe}-\mathrm{AM}$ & 64.53 & 16.67 & 300 \\
\hline
\end{tabular}

The magnetic properties of $\gamma-\mathrm{Fe}_{2} \mathrm{O}_{3}$ and $5 \mathrm{Co}-\mathrm{Fe}$ before and after magnetization (5Co-Fe-BM and $5 \mathrm{Co}-\mathrm{Fe}-\mathrm{AM})$ are measured by vibrating sample magnetometer (VSM) at normal temperature. Figure. 10 shows the relation of the applied external magnetic field (M-H curve) and samples magnetization. The embedded figure shows a good hysteresis loop indicates that the samples exhibit ferrimagnetic characteristics. Table 3 shows the magnetic performance index of saturation magnetization (Ms), remnant magnetizations (Mr)and coercive field ( $\mathrm{Hc}$ ) about catalysts of $\gamma-\mathrm{Fe}_{2} \mathrm{O}_{3}$, 5Co-Fe-BM and 5Co-Fe-AM. The introduction of Co causes the parameters of magnetic enhancement slightly, because the $\gamma-\mathrm{Fe}_{2} \mathrm{O}_{3}$ has high $\mathrm{Ms}$, but the $\mathrm{Mr}$ and $\mathrm{Hc}$ obviously increase.(21) The increase of the magnetic parameters are related with cobalt ions which have higher spin electrons (56) and the effect of exchange interaction exists in electron spins that trapped on oxygen vacancies (57). And Hc increases to 300 Oe after magnetization because the unidirectional spin electrons in the magnetic domain of the sample increase.(55) The (Ms) value of $\gamma-\mathrm{Fe}_{2} \mathrm{O}_{3}$ around 
$60 \mathrm{emu} / \mathrm{g}$, smaller than that of massive $\gamma-\mathrm{Fe}_{2} \mathrm{O}_{3}$ (i.e. $73.5 \mathrm{emu} / \mathrm{g}$ ) which is caused by surface spin canting effect.(58-60) It also indicates that the magnetic properties of $\mathrm{Fe}_{3} \mathrm{O}_{4}$ intermediates don't weaken remarkable after the calcination treatment, so $\gamma-\mathrm{Fe}_{2} \mathrm{O}_{3}$ maintains the magnetic properties near to the $\mathrm{Fe}_{3} \mathrm{O}_{4}$ intermediate products.(49) But according to previous reports, with the increase in the amount of Co doped, the magnetic properties of the samples should show a change trend to increase first and then decrease.(31,59) So the 5Co-Fe with best catalytic activity may have the strongest magnetic properties.

\subsection{In situ DRIFTS results}
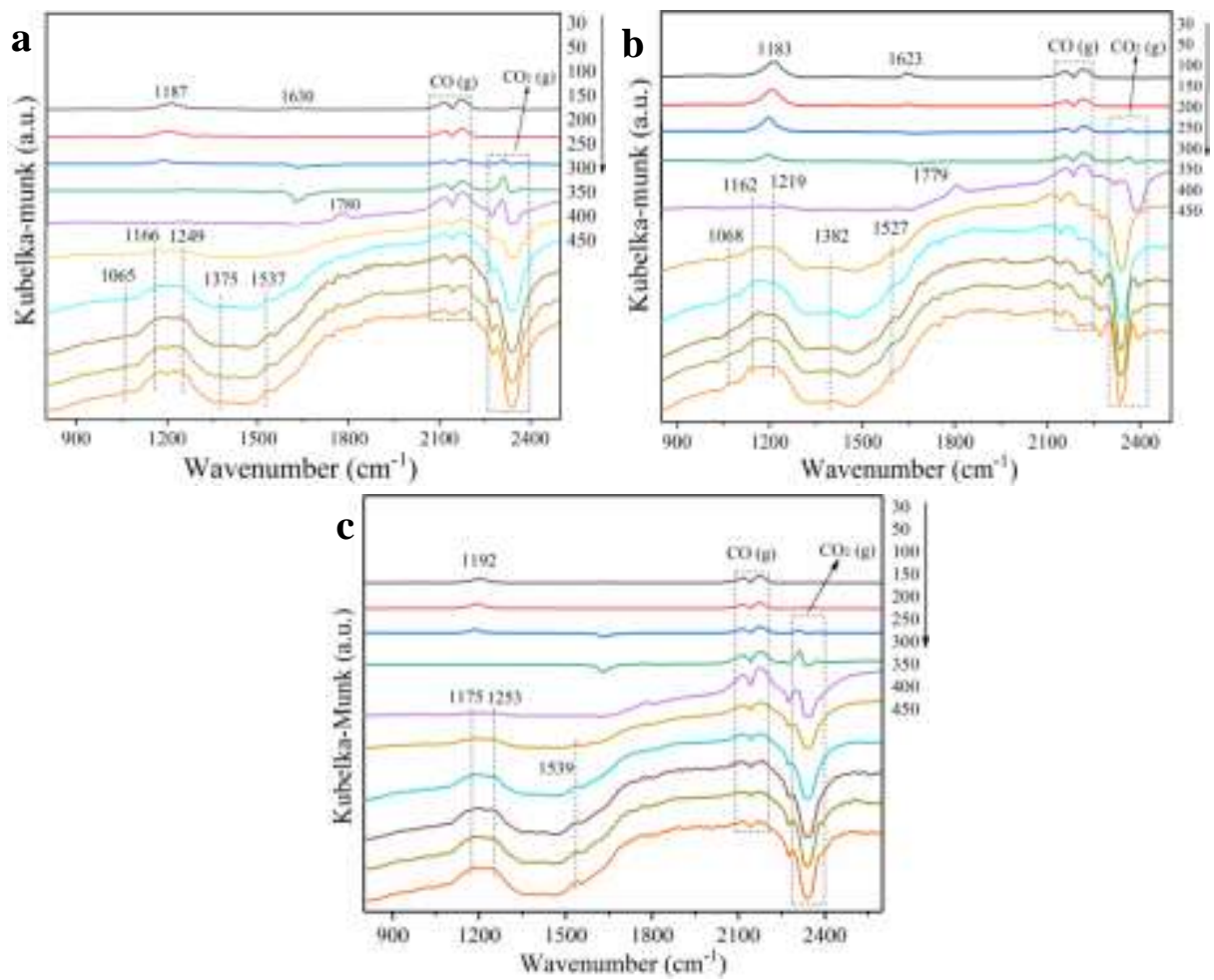

Figure 11. In situ DRIFTS results in CO atmosphere interaction with (a) 5Co-Fe-BM, (b) $5 \mathrm{Co}-\mathrm{Fe}-\mathrm{AM}$ and (c) pure $\gamma-\mathrm{Fe}_{2} \mathrm{O}_{3}$ catalysts $\left(30-450{ }^{\circ} \mathrm{C}\right)$

To expose the influence of magnetism on the adsorption of reaction gas and catalytic reduction mechanism on magnetic catalyst, infrared spectroscopy is measured. The in situ DRIFTS spectra are obtained in $\mathrm{CO}, \mathrm{NO}$ and $\mathrm{CO}+\mathrm{NO}$ atmospheres between $30-450{ }^{\circ} \mathrm{C}$, respectively. As shows in Figure. 11 is the FT-IR results of the catalysts in $\mathrm{CO}$ atmosphere, it can be seen that the addition of Co has no obvious effect on $\mathrm{CO}$ adsorption, and the peak at $1183-1187 \mathrm{~cm}^{-1}$ on $5 \mathrm{Co}-\mathrm{Fe}-\mathrm{AM}$ is 
slightly stronger than 5Co-Fe-BM, but the others are approximately same at all temperature points. During $30-100{ }^{\circ} \mathrm{C}$, little $\mathrm{CO}$ is adsorbed on the catalyst, and only the absorption peak of vibration mode of bicarbonate $(\mathrm{C}-\mathrm{O} \cdots \mathrm{H})$ is observed at 1187 $\mathrm{cm}^{-1}$. However, between 150 and $200{ }^{\circ} \mathrm{C}$, there are almost only adsorption peaks of gas phase $\mathrm{CO}$ and weaker $\mathrm{CO}_{2}$. As the temperature rises above $250{ }^{\circ} \mathrm{C}$, peaks of some new carbonate species appear: the absorption peaks at 1065-1068 $\mathrm{cm}^{-1}$ and 1239-1249 $\mathrm{cm}^{-1}$ belong to the vibration mode of monodentate carbonate $\left(v(\mathrm{CO})\right.$ and $v_{\mathrm{s}}\left(\mathrm{CO}_{3}{ }^{2-}\right)$, peaks at $1162-1166 \mathrm{~cm}^{-1}$ is the symmetrical vibration absorption peak of carbonate, and the vibration mode absorption peaks of carboxylate $\left(v_{\mathrm{s}}\left(\mathrm{COO}^{-}\right)\right.$and $\left.v_{\mathrm{as}}\left(\mathrm{COO}^{-}\right)\right)$ appear at $1378-1383 \mathrm{~cm}^{-1}$ and $1527-1537 \mathrm{~cm}^{-1}$, peaks of CO around $2109-2117 \mathrm{~cm}^{-1}$, respectively.(2,61) Figure 10. indicates that before $150{ }^{\circ} \mathrm{C}$, little $\mathrm{CO}$ captured on the catalyst surface. The peak at $1187 \mathrm{~cm}^{-1}$ almost disappears due to the thermal decomposition and trace reduction of $\mathrm{CO}_{\mathrm{x}}$ to $\mathrm{CO}_{2}$ at $150-200{ }^{\circ} \mathrm{C}$, so only $\mathrm{CO}$ and $\mathrm{CO}_{2}$ peaks appeared. At $200{ }^{\circ} \mathrm{C}$, the catalyst reaches the active temperature point, promoting $\mathrm{CO}$ to produce a series of reactions on the catalyst to produce different carbonate species carboxylate species and $\mathrm{CO}_{2}$. Though $\mathrm{CO}$ is an electron body with three bonds between intramolecular $\mathrm{C}$ and $\mathrm{O}(38)$, there is no single electron so it does not have paramagnetism and can't be adsorbed by the additional magnetic field generated by the catalyst. 

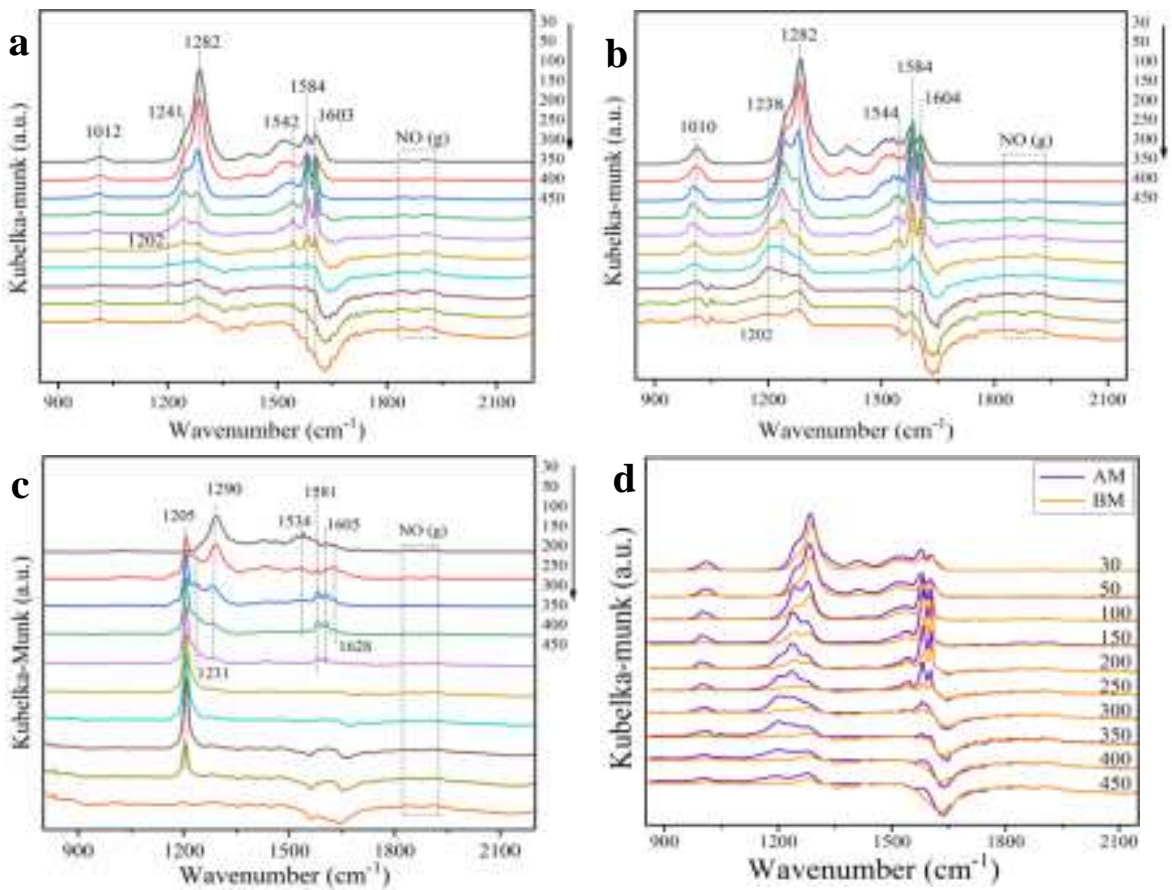

Figure 12. FT-IR results of $\mathrm{NO}$ atmosphere interaction with (a) 5Co-Fe-BM, (b) 5Co-Fe-AM (c) and pure $\gamma-\mathrm{Fe}_{2} \mathrm{O}_{3}$, (d) contrast of $5 \mathrm{Co}-\mathrm{Fe}-\mathrm{AM}$ and $5 \mathrm{Co}-\mathrm{Fe}-\mathrm{BM}$

Figure. 12 reveals the interaction between the NO and the sample surface components. From Figure. 12(a, b), the difference of NO adsorption between 5Co-Fe-AM and $5 \mathrm{Co}-\mathrm{Fe}-\mathrm{BM}$ are hardly observed in the range of $30-450{ }^{\circ} \mathrm{C}$, because their spectra are similar. The peaks show at 1012-1013 and $1605 \mathrm{~cm}^{-1}$ belong to the vibrational peaks of bridging dinitrate $(\mathrm{N}=\mathrm{O})(1)$, and peaks at 1202 and 1542-1543 $\mathrm{cm}^{-1}$ are symmetric and asymmetric vibrational modes chelating bidentate nitrates. Both of them trend to increase first and then decrease to disappear with the increase of temperature. Absorption peaks at $1240-1241$ and $1578-1578 \mathrm{~cm}^{-1}$ correspond to the vibration of chelate bidentate nitrate $(4,62)$. A large number of monodentate nitrate absorption peaks appear at $1285-1286 \mathrm{~cm}^{-1}$ form, and the adsorption peak of gas phase NO is $1843-1903 \mathrm{~cm}^{-1}$.(61) But it can be clearly seen from Figure. 12(d), the adsorption band intensity of all $\mathrm{NO}_{\mathrm{x}}$ species of 5Co-Fe-AM is strong, especially the vibration peaks of chelated bidentate nitrate at 1240 and $1578 \mathrm{~cm}^{-1}$, which may result from that magnetic field has stronger adsorption for chelating bidentate nitrate species.(55) So the magnetized catalyst with stronger magnetic field can adsorb more paramagnetic $\mathrm{NO}$ molecule on the catalyst to form $\mathrm{NO}_{\mathrm{x}}$ multi-species, in another word, the magnetized catalyst with higher magnetic field can make paramagnetic NO 
adsorb on the catalyst to form $\mathrm{NO}_{\mathrm{x}}$. The reason why the spectral band intensity of the sample after magnetization decreases slowly at relatively high temperature may be that $\mathrm{NO}_{\mathrm{x}}$ is relatively difficult to desorb/transform/dissociate from the catalyst surface due to the mutual attraction of magnetic attraction. When the temperature is $450{ }^{\circ} \mathrm{C}$, the peak intensity of 5Co-Fe-AM is keeping higher than that corresponding to 5Co-Fe-BM, but the difference decreases significantly, indicating that the magnetic properties of the catalyst will gradually weaken with temperature increasing.

At $30-150{ }^{\circ} \mathrm{C}$, the NO captured by oxygen vacancies on the catalyst then to form various nitrate species. Before reaching the active temperature point, the NO attached to surface of the catalyst to form nitrate and nitrite without conversion and decomposition into $\mathrm{N}_{2}$. As temperature rise further, the peak intensity of linear nitrite, monodentate nitrate at 1240 and $1285 \mathrm{~cm}^{-1}$ sharply decrease, while the peak intensity of bridging bidentate nitrate and chelating bidentate nitrate in 1543 and $1605 \mathrm{~cm}^{-1}$ increase slightly. This indicates that these unstable monodentate nitrates transition to more stable chelate bidentate nitrates as the temperature increases.(32) Combined with Figure. 2(a, c), the NO adsorption changes at $150-200{ }^{\circ} \mathrm{C}$, but the $\mathrm{N}_{2}$ yield almost remains unchanged, meaning that $\mathrm{NO}$ basically converted to $\mathrm{NO}_{\mathrm{x}}$ intermediates. After $250{ }^{\circ} \mathrm{C}$, the peak intensity of all nitrate species decreases, indicating that these instability intermediate products begin decomposition and desorption. Nearly all $\mathrm{NO}_{\mathrm{x}}$ species disappeared at $350{ }^{\circ} \mathrm{C}$, which is consistent with NO $100 \%$ conversion at $350{ }^{\circ} \mathrm{C}$ in Figure. 2(a). Figure. 12(d) shows the difference of $\mathrm{NO}$ adsorption intensity between the 5Co-Fe-BM and 5Co-Fe-AM more clearly, the adsorption band intensity of all $\mathrm{NO}_{\mathrm{x}}$ species of $5 \mathrm{Co}-\mathrm{Fe}-\mathrm{AM}$ is strong indicating that the magnetized catalyst with higher magnetic field can absorb more paramagnetic NO on the surface to form $\mathrm{NO}_{\mathrm{x}}$ species.

However, after compared Figure. 12(a) with (c), there are two major peaks ascribed to pure $\gamma-\mathrm{Fe}_{2} \mathrm{O}_{3}$, one at $1290 \mathrm{~cm}^{-1}$ attributes to monodentate nitrate adsorbed at room temperature and its peak intensity decreased with increasing temperature, and at $1205 \mathrm{~cm}^{-1}$ is chelate bidentate nitrate symmetric vibrational modes, which increases firstly then decrease with temperature rise, the others peak value is not obvious. It is 
easy to see that the introduction Co clearly promotes formation of more $\mathrm{NO}_{\mathrm{x}}$ species, the absorption peaks at 1282 and $1500-1600 \mathrm{~cm}^{-1}$ increase significantly, but the peak intensity of the chelate bidentate nitrate at $1205 \mathrm{~cm}^{-1}$ decreased. The addition of $\mathrm{Co}^{2+}$ is beneficial to the oxidation of $\mathrm{NO}$ adsorbed on the catalyst turn to unstable monodentate nitrate and inhibits the formation of stable chelate bidentate nitrate.
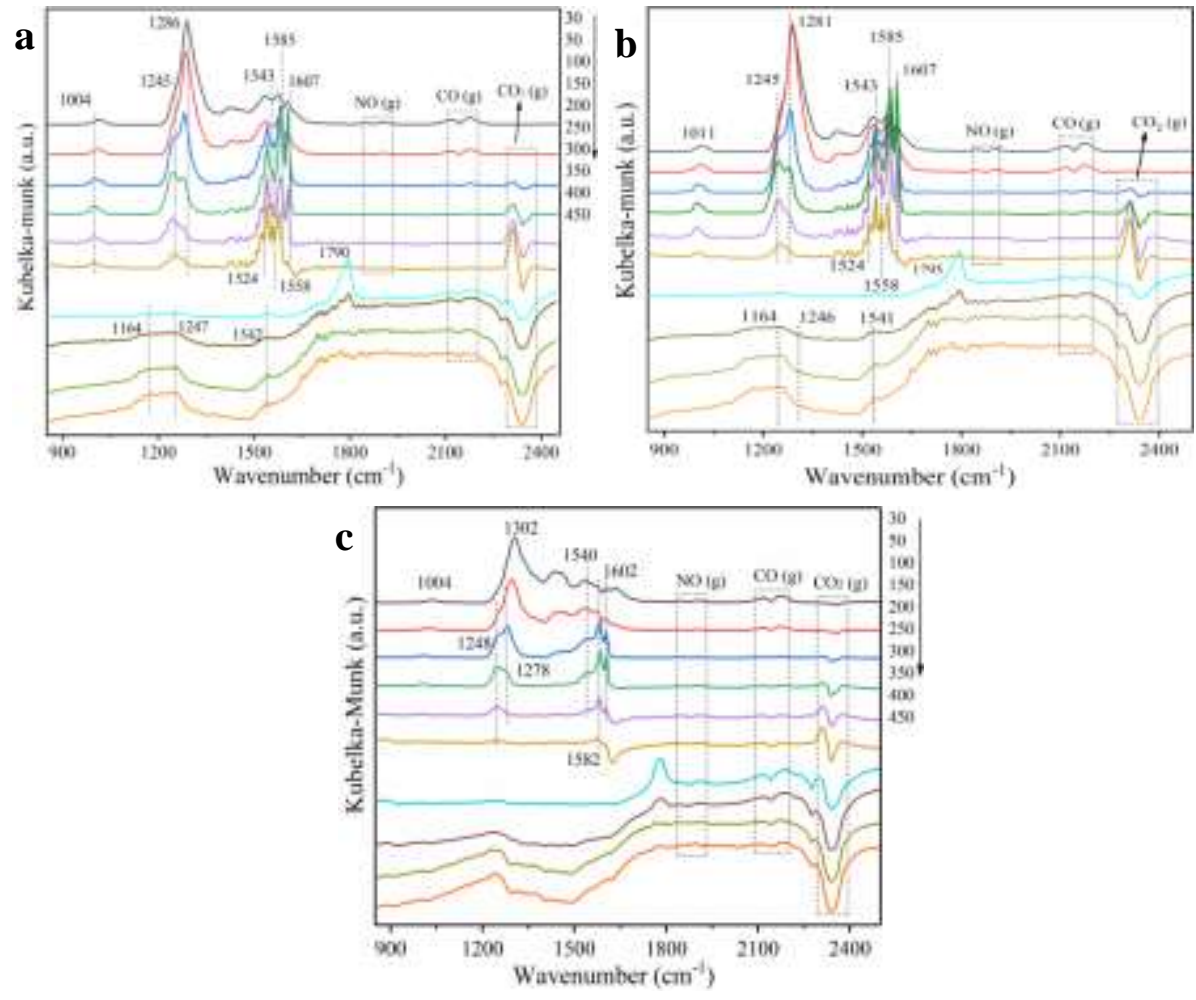

Figure. 13. FT-IR results of (a) 5Co-Fe-BM, (b) 5Co-Fe-AM and (c) $\gamma-\mathrm{Fe}_{2} \mathrm{O}_{3}$ at each temperature in $\mathrm{NO}+\mathrm{CO}$ atmosphere, respectively

The in situ DRIFTS results of 5Co-Fe-BM, 5Co-Fe-AM and $\gamma-\mathrm{Fe}_{2} \mathrm{O}_{3}$ in $\mathrm{CO}+\mathrm{NO}$ mixed atmosphere are shown in Figure. 13. From Figure. 13 (a, b), it can see that before $250^{\circ} \mathrm{C}$, tow spectra are basically similar to that NO single adsorption (Figure. 12). These peaks at 1004-1011 and $1607 \mathrm{~cm}^{-1}, 1205$ and $1543 \mathrm{~cm}^{-1}, 1281-1286 \mathrm{~cm}^{-1}$, 1240 and $1578 \mathrm{~cm}^{-1}, 1285-1286 \mathrm{~cm}^{-1}, 1364 \mathrm{~cm}^{-1}$ and $1843-1903 \mathrm{~cm}^{-1}$ are designated as vibrational peaks of bridging dinitrate $(\mathrm{N}=\mathrm{O})$, weak adsorption peaks of chelating bidentate nitrate chelating dinitrate, chelating dinitrate, monodentate nitrate, free $\mathrm{NO}_{3}{ }^{-}$, and the adsorption peaks of gas NO, respectively.(55) Furthermore, two peaks at 1524 and $1558 \mathrm{~cm}^{-1}$ can be assigned to monodentate nitrate and chelate bidentate nitrate, respectively. Figure. 13(c) shows the in FT-IR results of $\gamma-\mathrm{Fe}_{2} \mathrm{O}_{3}$, the peak positions are identical with $5 \mathrm{Co}-\mathrm{Fe}$ basically, but the peak intensity is obviously lower than that 
of $5 \mathrm{Co}-\mathrm{Fe}$, which is same with the activity results. Meanwhile, except the adsorption peak of gas CO in $2100-2200 \mathrm{~cm}^{-1}$, there is no bicarbonate peak at $1187 \mathrm{~cm}^{-1}$ which exists in CO single adsorption.(40) The peaks at $2300-2400 \mathrm{~cm}^{-1}$ that appear with the increase of temperature are $\mathrm{CO}_{2}$.

It can be seen that NO preferentially adsorbs on the catalyst surface in mixed atmosphere, which also inhibits $\mathrm{CO}$ adsorption to a certain extent, because no carbonate or carboxylate peaks were observed in this temperature range $\left(<250^{\circ} \mathrm{C}\right)$. Another reason that the NO occupies more oxygen vacancies, resulting in the rapid formation of all kinds of nitrate intermediates on the catalyst, which also inhibits $\mathrm{CO}$ adsorbed on the catalyst to form carbonates. Carefully compared 5Co-Fe-BM and $5 \mathrm{Co}-\mathrm{Fe}-\mathrm{AM}$, the absorption peaks vibration of chelate bidentate nitrate at $1587 \mathrm{~cm}^{-1}$ still can be observed above $300{ }^{\circ} \mathrm{C}$, confirming that the sample magnetized with stronger magnetic properties can adsorbed more NO to form nitrate species.

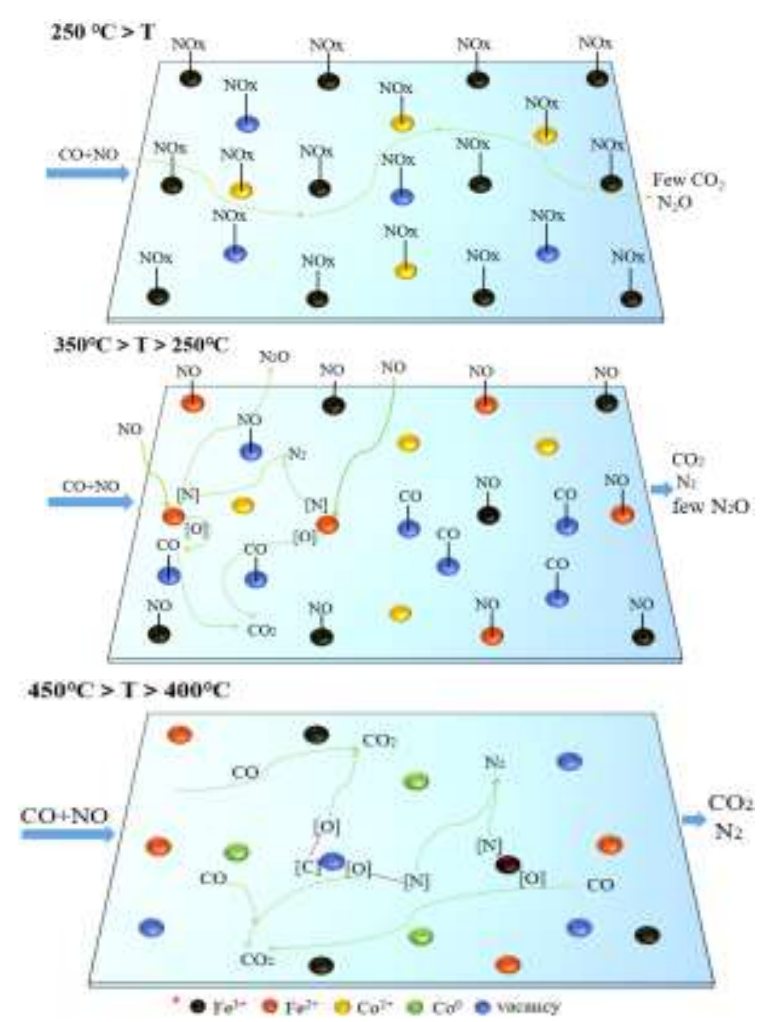

Figure 14. schematic diagram of a possible reaction mechanism for CO-SCR on $5 \mathrm{Co}-\mathrm{Fe}$ catalyst

Based on the results and discussions above, a possible reaction mechanism for $\mathrm{NO}+\mathrm{CO}$ reaction over magnetic $\gamma-\mathrm{xCoFe}_{2} \mathrm{O}_{3}$ catalyst is preliminarily proposed, as shown in Figure. 14 . Within $30-250{ }^{\circ} \mathrm{C}$, when catalysts surface exposed to the mixed 
atmosphere of $\mathrm{NO}+\mathrm{CO}, \mathrm{NO}$ is preferentially adsorbed on surface then to form $\mathrm{NO}_{\mathrm{x}}$ species due to their unpaired electrons, and the magnetic field of the catalyst also promotes NO adsorption, while inhibits the adsorption of CO. From Figure. 12 and Figure. 13, it can be seen that both the introduction of Co and magnetization can promote this process, that is, the magnetic enhancement is in favour of the adsorption of $\mathrm{NO}$ on the catalyst. As increasing of temperature, the $\mathrm{NO}_{\mathrm{x}}$ species adsorbed on the vacancy are dissociated into radicals $[\mathrm{N}]$ and $[\mathrm{O}]$, and $\mathrm{CO}$ molecules can capture reactive oxygen species, which weaken the $\mathrm{N}-\mathrm{O}$ bond and facilitates the dissociation of the $\mathrm{NO}_{\mathrm{x}}$ species. Meanwhile, after $\mathrm{CO}$ molecules react with $[\mathrm{O}]$ to form $\mathrm{CO}_{2}$, the other $[\mathrm{N}]$ can combine with $\mathrm{NO}$ to form $\mathrm{N}_{2} \mathrm{O}$ or with another $[\mathrm{N}]$ to come into being $\mathrm{N}_{2}$.(32) With higher temperature, gaseous $\mathrm{CO}$ molecules and another [N] react with $[\mathrm{O}],[\mathrm{N}]$ generated by $\mathrm{NO}$ on oxygen vacancy to generate $\mathrm{CO}_{2}$ and $\mathrm{N}_{2} .(62)$ Apparently, at lower temperatures, gas $\mathrm{CO}$ molecules react with the $\mathrm{NO}_{\mathrm{x}}$ attracted on catalyst surface; at higher temperatures, $\mathrm{CO}$ react with free radicals $([\mathrm{O}])$ produced by catalysts' oxygen vacancies, so the catalyst follows the Langmuir-Hinshlwood (L-H) mechanism at low temperatures and Eley-Rideal (E-R) mechanisms at high temperatures, respectively.(32,55,40)

\section{Conclusions}

The study synthesized pure and Co-doped (0-9\%) bayberry-like microspheres $\gamma-\mathrm{Fe}_{2} \mathrm{O}_{3}$ by solvothermal method. The results show that the $5 \mathrm{Co}-\mathrm{Fe}$ catalyst with maximum surface area has the best catalytic performance, and a bit of Co doping to the samples is independent of the structure and morphology of bayberry microspheres, but it will affect specific surface area and magnetism, which are the major factors in the catalytic activity. And the introduction of Co promotes the NO to form easily decomposed monodentate nitrate and inhibits the formation of more stable chelate bidentate nitrate. Comparing the activity of 5Co-Fe-AM and 5Co-Fe-BM, it can be seen that the catalysts with high magnetism will promote the adsorption and reduction of more paramagnetic NO molecules, which improves activity.

\section{Supporting Information}


ASSOCIATED CONTENT Supporting Information Available:

**[Among many metal oxides, ferric oxide are the important transition metal oxide species, and $\gamma-\mathrm{Fe}_{2} \mathrm{O}_{3}$ as one of the special phases has magnificent application prospects, because of magnetic properties and biocompatibility. Although both $\alpha-\mathrm{Fe}_{2} \mathrm{O}_{3}$ and $\gamma-\mathrm{Fe}_{2} \mathrm{O}_{3}$ phases belong to $\mathrm{Fe}_{2} \mathrm{O}_{3}$, in the application of CO-SCR, their catalytic performances are different, $\gamma-\mathrm{Fe}_{2} \mathrm{O}_{3}$ shows better catalytic performance than $\alpha-\mathrm{Fe}_{2} \mathrm{O}_{3}$ because of it possesses magnetic and more surface acid sites. But the catalytic performance of pure $\mathrm{Fe}_{2} \mathrm{O}_{3}$ is poor at low temperature, so the manuscript through Co-doping to improve its physicochemical properties in order to improve the catalytic performance. $]^{* *}$

\section{Author Information}

\section{Corresponding Author}

Bin Li - School of Chemistry and Chemical Engineering, Guangxi University, Daxue East Road 100, Nanning 530004, P. R. China; iD: 0000-0002-4080-3268 E-mail: binli@gxu.edu.cn

\section{Authors}

Xuemei Ou - Guangxi University, School of Chemistry and Chemical Engineering, Guangxi University, Daxue East Road 100, Nanning 530004, P. R. China

Kean Chen - Guangxi University, School of Chemistry and Chemical Engineering, Guangxi University, Daxue East Road 100, Nanning 530004, P. R. China

Longqing Wei - Guangxi University, School of Chemistry and Chemical Engineering, Guangxi University, Daxue East Road 100, Nanning 530004, P. R. China

Yaqian Deng - Guangxi University, School of Chemistry and Chemical Engineering, Guangxi University, Daxue East Road 100, Nanning 530004, P. R. China

Ju Li - Guangxi University, School of Chemistry and Chemical Engineering, Guangxi University, Daxue East Road 100, Nanning 530004, P. R. China

Lihui Dong - Guangxi University, School of Chemistry and Chemical Engineering, 
Guangxi University, Daxue East Road 100, Nanning 530004, P. R. China

\section{Author Contributions}

Xuemei Ou: performed the investigation, conceptualization research, analysis and drafted the manuscript. Kean Chen, Longqing Wei and Yaqian Deng: achieved formal analysis, modify and validation the section. Bin $\mathrm{Li}$ and Lihui Dong led the bibliographic research and drafted the project, determine the final manuscript.

\section{Notes}

All authors state that they have no known competing financial benefit or personal relationships that seem have influence to the work reported in this paper.

\section{ACKNOWLEDGMENTS}

This work is supported by Program for Science and Technology Development Plan of Nanning (No. 20163146), National Natural Science Foundation of China (No. 21763003, 21663005). 


\section{REFERENCES}

1.Dai, X.; Jiang, W.; Wang, W.; Weng, X.; Shang, Y.; Xue, Y.; Wu, Z., Supercritical Water Syntheses of Transition Metal-doped $\mathrm{CeO}_{2}$ Nano-Catalysts for Selective Catalytic Reduction of NO by CO: An in situ Diffuse Reflectance Fourier Transform Infrared Spectroscopy Study. Chinese J. Catal. 2018, 39 (4), 728-735.

2.Yao, X.; Xiong, Y.; Zou, W.; Zhang, L.; Wu, S.; Dong, X.; Gao, F.; Deng, Y.; Tang, C.; Chen, Z.; Dong, L.; Chen, Y., Correlation Between the Physicochemical Properties and Patalytic Performances of $\mathrm{Ce}_{x} \mathrm{Sn}_{1-}$ ${ }_{x} \mathrm{O}_{2}$ Mixed Oxides for NO Reduction by CO. APPL CATAL B-ENVIRON 2014, 144, 152-165.

3.Bahrami, S.; Niaei, A.; Illán-Gómez, M. J.; Tarjomannejad, A.; Mousavi, S. M.; Albaladejo-Fuentes, V., Catalytic Reduction of $\mathrm{NO}$ by $\mathrm{CO}$ over $\mathrm{CeO}_{2}-\mathrm{MO}_{x}(0.25)(\mathrm{M}=\mathrm{Mn}$, Fe and $\mathrm{Cu}$ ) Mixed Oxides-Modeling and Optimization of Catalyst Preparation by Hybrid ANN-GA. J ENVIRON CHEM ENG 2017, 5 (5), 4937-4947.

4.Lv, Y.; Zhang, H.; Yao, X.; Dong, L.; Chen, Y., Investigation of the Physicochemical Properties of $\mathrm{CuO} / \mathrm{Sm}_{2} \mathrm{O}_{3} / \mathrm{\gamma}-\mathrm{Al}_{2} \mathrm{O}_{3}$ Catalysts and Their Activity for NO Removal by CO. J MOL CATAL A-CHEM 2016, 420, 34-44.

5.Fan, A.; Qin, C.; Zhang, X.; Dai, X.; Dong, Z.; Luan, C.; Yu, L.; Ge, J.; Gao, F., Phosphorus-Doped FeNi Alloys $/ \mathrm{NiFe}_{2} \mathrm{O}_{4}$ Imbedded in Carbon Network Hollow Bipyramid as Efficient Electrocatalysts for Oxygen Evolution Reaction. ACS Sustain. Chem. Eng. 2018, 7 (2), 2285-2295.

6.Salker, A. V.; Desai, M. S. F., Catalytic Activity and Mechanistic Approach of NO Reduction by CO over $\mathrm{M}_{0.05} \mathrm{CO}_{2.95} \mathrm{O}_{4}(\mathrm{M}=\mathrm{Rh}, \mathrm{Pd} \& \mathrm{Ru})$ Spinel System. Catal Commun 2016, 389, 344-353.

7.Rezaei, P.; Rezaei, M.; Meshkani, F., Ultrasound-Assisted Hydrothermal Method for the Preparation of the $\mathrm{M}-\mathrm{Fe}_{2} \mathrm{O}_{3}-\mathrm{CuO}$ (M: Mn, Ag, Co) Mixed Oxides Nanocatalysts for Low-Temperature CO Oxidation. Ultrason Sonochem 2019, 57, 212-222.

8.Bai, Y.; Bian, X.; Wu, W., Catalytic Properties of $\mathrm{CuO} / \mathrm{CeO}_{2}-\mathrm{Al}_{2} \mathrm{O}_{3}$ Catalysts for Low Concentration NO Reduction with CO. Appl. Surf. Sci. 2019, 463, 435-444.

9.Boon, Y. H.; Mohamad Zain, N. N.; Mohamad, S.; Osman, H.; Raoov, M., Magnetic Poly( $\beta$-cyclodextrin-ionic liquid) Nanocomposites for Micro-Solid Phase Extraction of Selected Polycyclic Aromatic Hydrocarbons in Rice Samples Prior to GC-FID Analysis. FOOD CHEM, 2019, 278, 322-332.

10.Liang, J.; Li, Z.; Ma, K.; Wu, X.; Wu, W.; Xia, J.; Huang, Y.; Huang, Y., Improved Magnetic Properties of $\mathrm{Co}_{0.5} \mathrm{La}_{\mathrm{x}} \mathrm{Fe}_{2.5-\mathrm{x}} \mathrm{O}_{4} / \mathrm{FeCo}$ Composite Powders by Magnetic Exchange-Coupling Effect. J. Magn. Magn. Mater. 2019, 491.

11.Tao, Q.; Bi, J.; Huang, X.; Wei, R.; Wang, T.; Zhou, Y.; Hao, H., Fabrication, Application, Optimization and Working Mechanism of $\mathrm{Fe}_{2} \mathrm{O}_{3}$ and Its Composites for Contaminants Elimination from Wastewater. Chemosphere 2021, 263.

12.Jia, Y.; Dong, L.; Ren, P.; Zhong, Me.; Ma, J.; Fan, X., Performances and Mechanism of Methyl Orange and Congo Red Adsorbed on the Magnetic lon-Exchange Resin. Chem. Eng. Data 2020, 65, 725-736

13.de Melo, E. J.; de Mesquita, J. P.; Pereira, M. C.; Duarte Cavalcante, L. C.; Santos Filho, E. d.; Domingos Fabris, J.; Ardisson, J. D.; Alves de Oliveira, L. C., Synthesis and Characterization of $\alpha \mathrm{Fe}_{2-x} \mathrm{M}$ 
${ }_{x} \mathrm{O}_{3}(\mathrm{M}=\mathrm{Co}, \mathrm{Ni}, \mathrm{Cu}$ or $\mathrm{Zn})$ Photocatalysts for the Degradation of the Indigo Carmine Dye in Water. Hyperfine Interact, 2017, 238(1), 2-11

14.Zhang, N.; Han, X.; Liu, Y.; Hu, X.; Zhao, Q.; Chen, J., 3D Porous Y- $\mathrm{Fe}_{2} \mathrm{O}_{3} @ \mathrm{C}$ Nanocomposite as High-Performance Anode Material of Na-Ion Batteries. ADV ENERGY MATER 2015, 5 (5).

15.Luby, Š.; Jergel, M.; Benkovičová, M.; Šiffalovič, P.; Ivančo, J.; Vegsö, K.; Majková, E.; Rella, R.;

Manera, M. G.; Capone, S.; Vávra, I., Sensitivity and Long-Term Stability of $\gamma-\mathrm{Fe}_{2} \mathrm{O}_{3}$ and $\mathrm{CoFe}_{2} \mathrm{O}_{4}$

Nanoparticle Gas Sensors for $\mathrm{NO}_{2}, \mathrm{CO}$ and Acetone Sensing - a Comparative Study. IEEE 2014, 1-4.

16.Ding, J.; Liu, L.; Xue, J.; Zhou, Z.; He, G.; Chen, H., Low-Temperature Preparation of Magnetically Separable $\mathrm{Fe}_{3} \mathrm{O}_{4} @ \mathrm{CuO}-\mathrm{RGO}$ Core-Shell Heterojunctions for High-Performance Removal of Organic Dye under Visible Light. J. Alloys Compd. 2016, 688, 649-656.

17.Ansari, F.; Sobhani, A.; Salavati-Niasari, M., Simple Sol-gel Synthesis and Characterization of New $\mathrm{CoTiO}_{3} / \mathrm{CoFe}_{2} \mathrm{O}_{4}$ Nanocomposite by using Liquid Glucose, Maltose and Starch as Fuel, Capping and Reducing Agents. J. Colloid Interface Sci. 2018, 514, 723-732.

18.Lemine, O. M.; Alanazi, A.; Albert, E. L.; Hjiri, M.; M’hamed, M. O.; Alrub, S. A.; Alkaoud, A.; Abdullah, C. A. C., $\mathrm{Y}-\mathrm{Fe}_{2} \mathrm{O}_{3} / \mathrm{Gd}_{2} \mathrm{O}_{3}$-Chitosan Magnetic Nanocomposite for Hyperthermia Application: Structural, Magnetic, Heating Efficiency and Cytotoxicity Studies. APPL PHYS A 2020, 126 (6).

19.Hao, J.; Shi, W., Transition metal (Mo, Fe, Co, and Ni)-based catalysts for electrochemical $\mathrm{CO}_{2}$ reduction. Chinese J. Catal. 2018, 39 (7), 1157-1166.

20.Salker, A. V.; Desai, M. S. F., CO-NO/O 2 Redox Reactions over Cu Substituted Cobalt Oxide Spinels. Catal Commun 2016, 87, 116-119.

21.Li, G.; Li, L.; Shi, J.; Yuan, Y.; Li, Y.; Zhao, W.; Shi, J., One-Pot Pyrolytic Synthesis of Mesoporous $\mathrm{MCO}_{2} \mathrm{O}_{4(4.5)}(\mathrm{M}=\mathrm{Mn}, \mathrm{Ni}, \mathrm{Fe}, \mathrm{Cu})$ Spinels and Its High Efficient Catalytic Properties for CO Oxidation at Low Temperature. J MOL CATAL A-CHEM 2014, 390, 97-104.

22.Sanaz, N-S.; Noroozian, E., Magnetic Solid-Phase Extraction and Determination of Ultra-Trace Amounts of Antimony in Aqueous Solutions using Maghemite Nanoparticles. Food Chemistry FOOD CHEM 2019.287,382-389.

23.Kiani, F.; Naeimi, H., Ultrasonic Accelerated Coupling Reaction using Magnetically Recyclable Bis (propyl molononitril) Ni Complex Nanocatalyst: A Novel, Green and Efficient Synthesis of Biphenyl Derivatives. Ultrason Sonochem 2018, 48, 267-274.

24.Ansari, N.; Feghhi, F., Montazeri, M.; Mohammadnejad, M.; Sheykhifard, Z.; Mohseni, S.M., Facile Synthesis of Water-Stable Iron Intercalated Multi Layered Graphene Nanocomposite with Large Magnetic Moments as Superior Water Pollutant Remediators. J. Colloid Interface Sci. 2019, 255.

25.Zambrzycki, C.; Shao, R.; Misra, A.; Streb, C.; Herr, U.; Güttel, R., Iron Based Core-Shell Structures as Versatile Materials: Magnetic Support and Solid Catalyst. catalysts. 2021, 11(72).

26. Ghasemi, H.; Aghabarari, B.; Alizadeh, M.; Khanlarkhani, A.; Abu-Zahra, N., High efficiency decolorization of wastewater by Fenton catalyst: Magnetic iron-copper hybrid oxides. J. Water Process. Eng. 2020, 37.

27. Galloni, M.; Campisi, S.; Marchetti, S.; Gervasini, A., Environmental Reactions of Air-Quality Protection on Eco-Friendly Iron-Based Catalysts. catalysts. 2020, 10.

28.Sun, X.; Ma, Y.; Xu, Y. F.; Xu, S.; Geng, B.; Dai, Z.; Zheng, G., Improved Magnetic Performance at Low and High Temperatures in Non-Exchange-Coupling $\mathrm{CoFe}_{2} \mathrm{O}_{4} / \mathrm{CoFe}_{2}$ Nanocomposites. J. Alloys Compd. 2015, 645, 51-56.

29.Luby, Š.; Ivančo, J.; Jergel, M.; Švec, P.; Kotlár, M.; Kostiuk, D.; Halahovets, J.; Kollár, J.; Mosnáček, J.; Majková, E., Thermal Stability of $\mathrm{y}^{-} \mathrm{Fe}_{2} \mathrm{O}_{3}$ Nanoparticles and Their Employment for Sensing of Acetone Vapours. J Phys Conf Ser 2017, 939. 


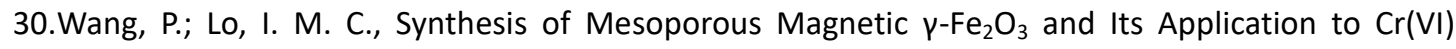
Removal from Contaminated Water. Water Res. 2009, 43 (15), 3727-3734.

31.Akbar, A.; Riaz, S.; Ashraf, R.; Naseem, S., Magnetic and Magnetization Properties of Co-Doped $\mathrm{Fe}_{2} \mathrm{O}_{3}$ Thin Films. IEEE Transactions on Magnetics 2014, 50 (8), 1-4.

32.Shi, X.; Chu, B.; Wang, F.; Wei, X.; Teng, L.; Fan, M.; Li, B.; Dong, L.; Dong, L., Mn-Modified CuO, $\mathrm{CuFe}_{2} \mathrm{O}_{4}$, and $y-\mathrm{Fe}_{2} \mathrm{O}_{3}$ Three-Phase Strong Synergistic Coexistence Catalyst System for NO Reduction by CO with a Wider Active Window. ACS Appl. Mater. Interfaces 2018, 10 (47), 40509-40522.

33.Qu, W.; Chen, Y.; Huang, Z.; Gao, J.; Zhou, M.; Chen, J.; Li, C.; Ma, Z.; Chen, J.; Tang, X., Active Tetrahedral Iron Sites of $y-\mathrm{Fe}_{2} \mathrm{O}_{3}$ Catalyzing NO Reduction by $\mathrm{NH}_{3}$. Environ. Sci. Technol. Lett 2017, 4 (6), 246-250.

34.Zhao, K.; Tang, H.; Qiao, B.; Li, L.; Wang, J., High Activity of $\mathrm{Au} / \mathrm{V}-\mathrm{Fe}_{2} \mathrm{O}_{3}$ for CO Oxidation: Effect of Support Crystal Phase in Catalyst Design. ACS Catal. 2015, 5 (6), 3528-3539.

35.Yuan, K.; Taylor, S. D.; Powell, B. A.; Becker, U., An ab initio Study of the Adsorption of $\mathrm{Eu}^{3+}, \mathrm{Pu}^{3+}$, $\mathrm{Am}^{3+}$, and $\mathrm{Cm}^{3+}$ Hydroxide Complexes on Hematite (001) Surface: Role of Magnetism on Adsorption. Surf Sci 2017, 664, 120-128.

36.Li, J.; Wang, S.; Zhou, L.; Luo, G.; Wei, F., NO Reduction by CO over a Fe-based Catalyst in FCC Regenerator Conditions. Chem. Eng.J. 2014, 255, 126-133.

37.Ben Dor, O.; Yochelis, S.; Radko, A.; Vankayala, K.; Capua, E.; Capua, A.; Yang, S.-H.; Baczewski, L. T.; Parkin, S. S. P.; Naaman, R.; Paltiel, Y., Magnetization Switching in Ferromagnets by Adsorbed Chiral Molecules without Current or External Magnetic Field. Nat. Commun. 2017, 8 (1).

38.Huang, C.-Q.; Li, W.-X., Influence of Nickel(II) Oxide Surface Magnetism on Molecule Adsorption: A First-Principles study. Chinese J. Catal. 2017, 38 (10), 1736-1748.

39.Jiang, W.; Zhang, X.; Sun, Z.; Fang, Y.; Li, F.; Chen, K.; Huang, C., Preparation and Mechanism of Magnetic Carbonaceous Polysaccharide Microspheres by Low-Temperature Hydrothermal Method. J. Magn. Magn. Mater. 2011, 323 (22), 2741-2747.

40.Liu, H.; Liu, L.; Wei, L.; Chu, B.; Qin, Z.; Jin, G.; Tong, Z.; Dong, L.; Li, B., Preparation of Three-Dimensionally Ordered Macroporous $\mathrm{MFe}_{2} \mathrm{O}_{4}(\mathrm{M}=\mathrm{Co}, \mathrm{Ni}, \mathrm{Cu})$ Spinel Catalyst and Its Simultaneous Catalytic Application in CO Oxidation and NO + CO Reaction. Fuel 2020, 272.

41. Zhang, Q.; Li, B.; Ma, Z.; Wang, Y.; Li, X.; One-Step Nanocasting Synthesis of Mesostructured Magnetic Fe/ $\mathrm{Y}-\mathrm{Fe}_{2} \mathrm{O}_{3} /$ Graphitic Carbon Composites. J. Alloys Compd. 2014, 617, 713-715.

42.Zhang, Z.; Zhang, Q.; Xu, L. n.; Xia, Y. b., Preparation of Nanometer $\mathrm{\gamma}-\mathrm{Fe}_{2} \mathrm{O}_{3}$ by an Electrochemical Method in Non-aqueous Medium and Reaction Dynamics. SYNTH REACT INORG M 2007, 37 (1), 53-56. 43.Qi, X.; Yan, Z.; Liu, Y.; Li, X.; He, G.; Komarneni, S., Ni and Co doped Yolk-Shell Type $\mathrm{Fe}_{2} \mathrm{O}_{3}$ Hollow Microspheres as Anode Materials for Lithium-Ion Batteries. MATER CHEM PHYS 2018, 211, 452-461.

44.Li, G.; Lan, J.; Li, G., Chrysanthemum-like 3D Hierarchical Magnetic $\gamma-\mathrm{Fe}_{2} \mathrm{O}_{3}$ and $\mathrm{Fe}_{3} \mathrm{O}_{4}$ Superstructures: Facile Synthesis and Application in Adsorption of Organic Pollutants from Water. RSC Advances 2015, 5 (3), 1705-1711.

45. Murugesan, C.; Okrasa L. O.; Chandrasekaran, G., Structural, AC conductivity, Impedance and Dielectric Study of Nanocrystalline $\mathrm{MFe}_{2} \mathrm{O}_{4}(\mathrm{M}=\mathrm{Mg}$, Co or $\mathrm{Cu}$ ) Spinel Ferrites. J Mater Sci: Mater Electron 2017, 28 13168-13175.

46.Xiong, W.; Zhao, Q.; Li, X.; Wang, L., Multifunctional Plasmonic Co-Doped $\mathrm{Fe}_{2} \mathrm{O}_{3} @$ Polydopamine-Au for Adsorption, Photocatalysis, and SERS-based Sensing. Particle \& Particle Systems Characterization 2016, 33 (9), 602-609.

47.Suresh, R.; Giribabu, K.; Manigandan, R.; Mangalaraja, R. V.; Solorza, J. Y.; Stephen, A.; Narayanan, V., Synthesis of $\mathrm{Co}^{2+}$-doped $\mathrm{Fe}_{2} \mathrm{O}_{3}$ Photocatalyst for Degradation of Pararosaniline Dye. SOLID STATE SCI 
2017, 68, 39-46.

48.Zhang, C.; Wang, J.; Yang, S.; Liang, H.; Men, Y., Boosting Total Oxidation of Acetone over Spinel $\mathrm{MCO}_{2} \mathrm{O}_{4}(\mathrm{M}=\mathrm{Co}, \mathrm{Ni}, \mathrm{Cu})$ Hollow Mesoporous Spheres by Cation-Substituting Effect. J. Colloid Interface Sci. 2019, 539, 65-75.

49.Zhu, L.-P.; Liao, G.-H.; Bing, N.-C.; Wang, L.-L.; Xie, H.-Y., Self-Assembly of $\mathrm{Fe}_{3} \mathrm{O}_{4}$ Nanocrystal-Clusters into Cauliflower-like Architectures: Synthesis and Characterization. J SOLID STATE CHEM 2011, 184 (9), 2405-2411.

50.Kazeminezhad, I.; Mosivand, S., Phase Transition of Electrooxidized $\mathrm{Fe}_{3} \mathrm{O}_{4}$ to $\gamma$ and $\alpha-\mathrm{Fe}_{2} \mathrm{O}_{3}$ Nanoparticles Using Sintering Treatment. Acta Physica Polonica A 2014, 125 (5), 1210-1214.

51.Wang, C.; Su, H.; Ma, Y.; Yang, D.; Dong, Y.; Li, D.; Wang, L.; Liu, Y.; Zhang, J., Coordination Polymers-Derived Three-Dimensional Hierarchical $\mathrm{CoFe}_{2} \mathrm{O}_{4}$ Hollow Spheres as High-Performance Lithium Ion Storage. ACS Appl. Mater. Interfaces 2018, 10 (34), 28679-28685.

52.Kong, H.; Lv, C.; Yan, C.; Chen, G., Engineering Mesoporous Single Crystals Co-Doped $\mathrm{Fe}_{2} \mathrm{O}_{3}$ for High-Performance Lithium Ion Batteries. Inorg. Chem. 2017, 56 (14), 7642-7649.

53.Wang, H.; Qu, Z.; Xie, H.; Maeda, N.; Miao, L.; Wang, Z., Insight into the Mesoporous $\mathrm{Fe}_{x} \mathrm{Ce}_{1-x} \mathrm{O}_{2-\delta}$ Catalysts for Selective Catalytic Reduction of $\mathrm{NO}_{\text {with }} \mathrm{NH}_{3}$ : Regulable Structure and Activity. J Catal 2016, 338, 56-67.

54.Bertocci, F.; Fort, A.; Mugnaini, M.; Vignoli, V.; Bertolucci, E.; Marracci, M.; Galletti, A. M. R.; Tellini, B., Fast Nano-Grained $\mathrm{Fe}_{3} \mathrm{O}_{4}$ Gas Sensor for the Control of $\mathrm{CO}$ and $\mathrm{NO}_{2}$ Concentrations. IEEE 2016, 286-290.

55.Liu, J.; Shi, X.; Liu, H.; Dong, L.; Li, B., Study on the Performance of Magnetic $\mathrm{Co}_{3} \mathrm{O}_{4} / \mathrm{Y}^{-}-\mathrm{Fe}_{2} \mathrm{O}_{3}$ Catalyst in NO + CO Reaction. Appl. Surf. Sci. 2020, 533.

56.Almessiere, M.A.; Slimani, Y.; Güner, S.; Nawaz, M.; Baykal, A.; Aldakheel, F.; Akhtar, S.; Ercan, I.; Belenli, İ.; Ozçelik, B., Magnetic and Structural Characterization of $\mathrm{Nb}^{3+}$-Substituted $\mathrm{CoFe}_{2} \mathrm{O}_{4}$ Nanoparticles. Ceram. Int. 2019, 45 (7), 8222-8232.

57. Mansour, H.; Omri, K.; Ammar, S., Structural, optical and magnetic properties of cobalt doped hematite nanoparticles. Chem. Phys. 2019, 110400

58.Zi, Z.; Sun, Y.; Zhu, X.; Yang, Z.; Dai, J.; Song, W., Synthesis and Magnetic Properties of $\mathrm{CoFe}_{2} \mathrm{O}_{4}$ Ferrite Nanoparticles. J. Magn. Magn. Mater. 2009, 321 (9), 1251-1255.

59.Asuha, S.; Gao, Y. W.; Deligeer, W.; Yu, M.; Suyala, B.; Zhao, S., Adsorptive Removal of Methyl Orange using Mesoporous Maghemite. J POROUS MAT 2011, 18, 581-587.

60.Tahar, L. B.; Smiri, L. S.; Artus, M.; Joudrier, A. L.; Herbst, F.; Vaulay, M. J.; Ammar, S.; Fiévet, F., Characterization and Magnetic Properties of Sm- and Gd-Substituted $\mathrm{CoFe}_{2} \mathrm{O}_{4}$ Nanoparticles Prepared by Forced Hydrolysis in Polyol. Mater. Res. Bull. 2007, 42 (11), 1888-1896.

61.Wang, L. Y.; Cheng, X. X.; Wang, Z. Q.; Ma, C. Y.; Qin, Y. K., Investigation on Fe-Co Binary Metal Oxides Supported on Activated Semi-Coke for NO Reduction by CO. Appl Catal B-Environ 2017, 201, 636-651.

62. Hadjiivanov, K. I., Identification of Neutral and Charged $\mathrm{N}_{\mathrm{x}} \mathrm{O}_{\mathrm{y}}$ Surface Species by IR Spectroscopy. CATAL. REV 2000, 42 (1-2), 71-144. 


\section{Table of Contents graphic}

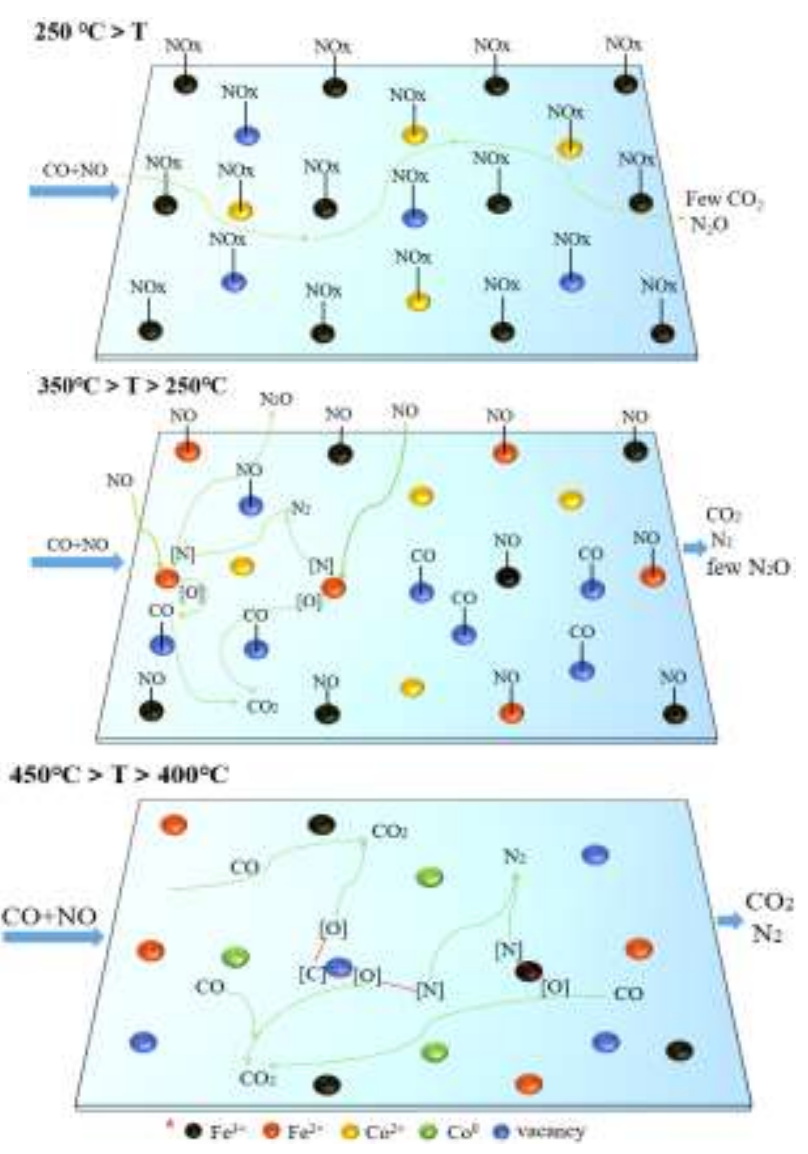




\section{Graphic for manuscript}

\section{Figure 1}

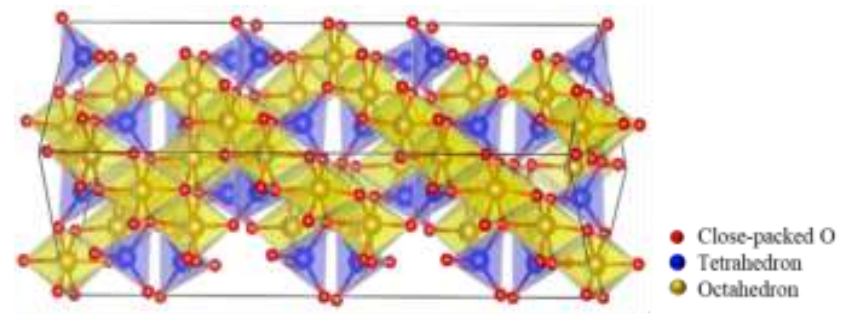

Figure $1 \gamma$-Fe2O3 cell units

Figure 2
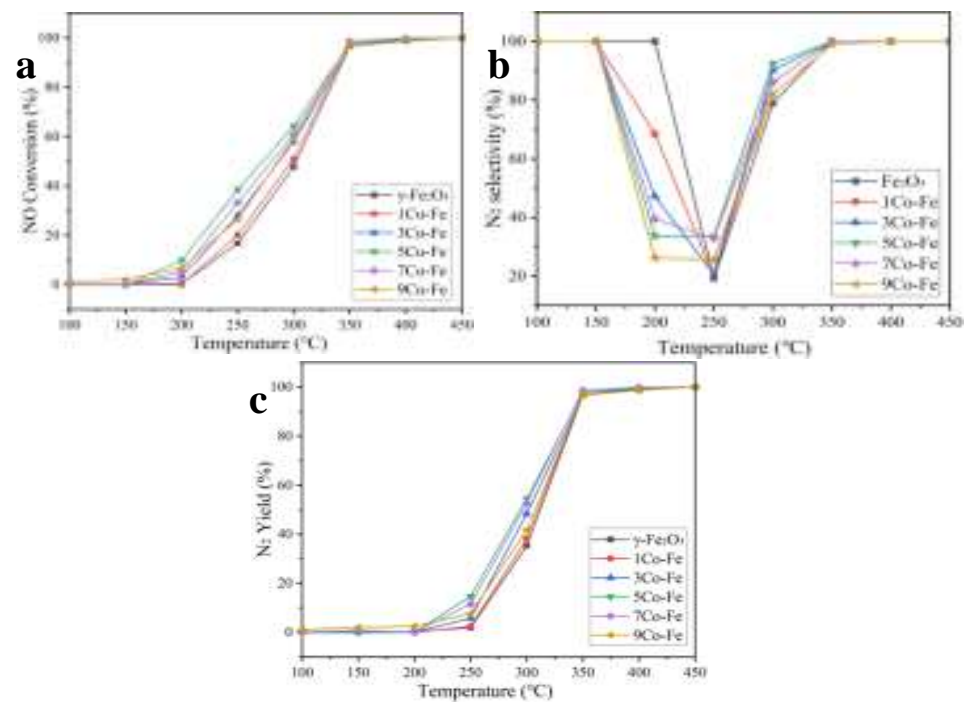

Figure 2. (a) $\mathrm{NO}$ conversion of $\gamma-\mathrm{xCoFe}_{2} \mathrm{O}_{3}$; (b) $\mathrm{N}_{2}$ selectivity of $\gamma-\mathrm{xCoFe}_{2} \mathrm{O}_{3}$; (c) yield of $\mathrm{N}_{2}$ of $\gamma-\mathrm{xCoFe}{ }_{2} \mathrm{O}_{3}$ at respective reaction temperatures;

\section{Figure 3}



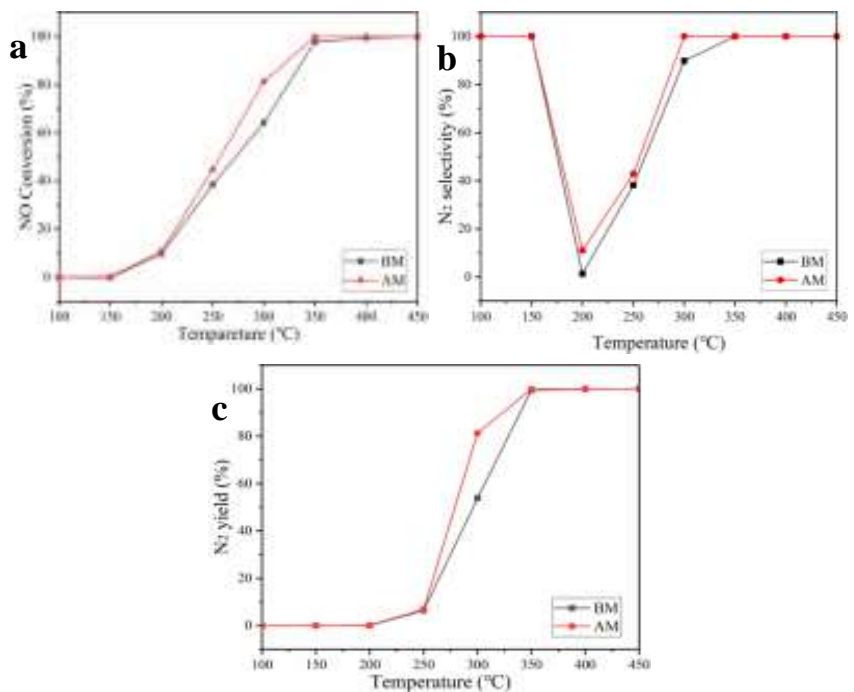

Figure 3. (a) NO conversion, (b) $\mathrm{N}_{2}$ selectivity and (c) yield of $\mathrm{N}_{2}$ of $5 \mathrm{Co}-\mathrm{Fe}$ sample before (BM) and after (AM) magnetization

\section{Figure 4}
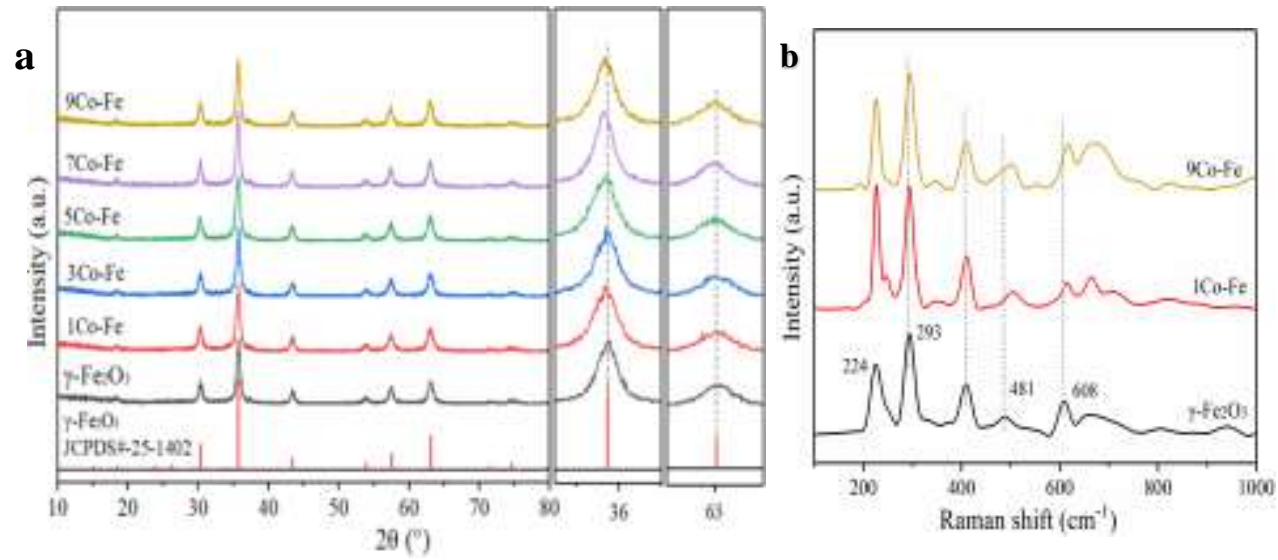

Figure 4. (a) Powder XRD patterns and (b) Raman spectra of $\gamma-\mathrm{xCoFe}_{2} \mathrm{O}_{3}$

\section{Figure 5}



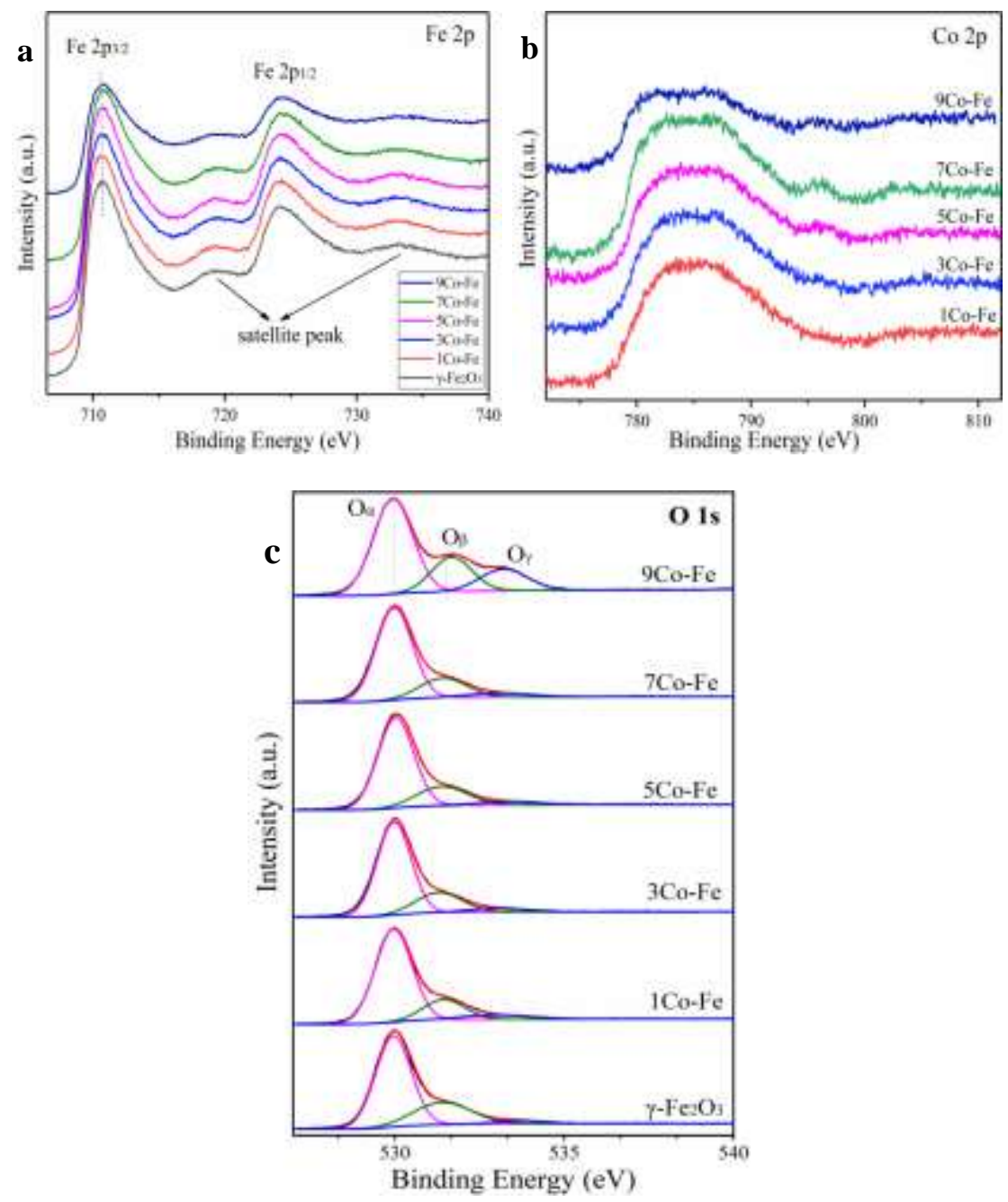

Figure 5. the XPS spectra: (a) $\mathrm{Fe} 2 \mathrm{p}$ of $\gamma-\mathrm{xCoFe} \mathrm{O}_{3}$, (b) Co 2p of 1-9Co-Fe and (c) $\mathrm{O} 1 \mathrm{~s}$ of $\gamma-\mathrm{xCoFe} \mathrm{O}_{3}$

\section{Figure 6}



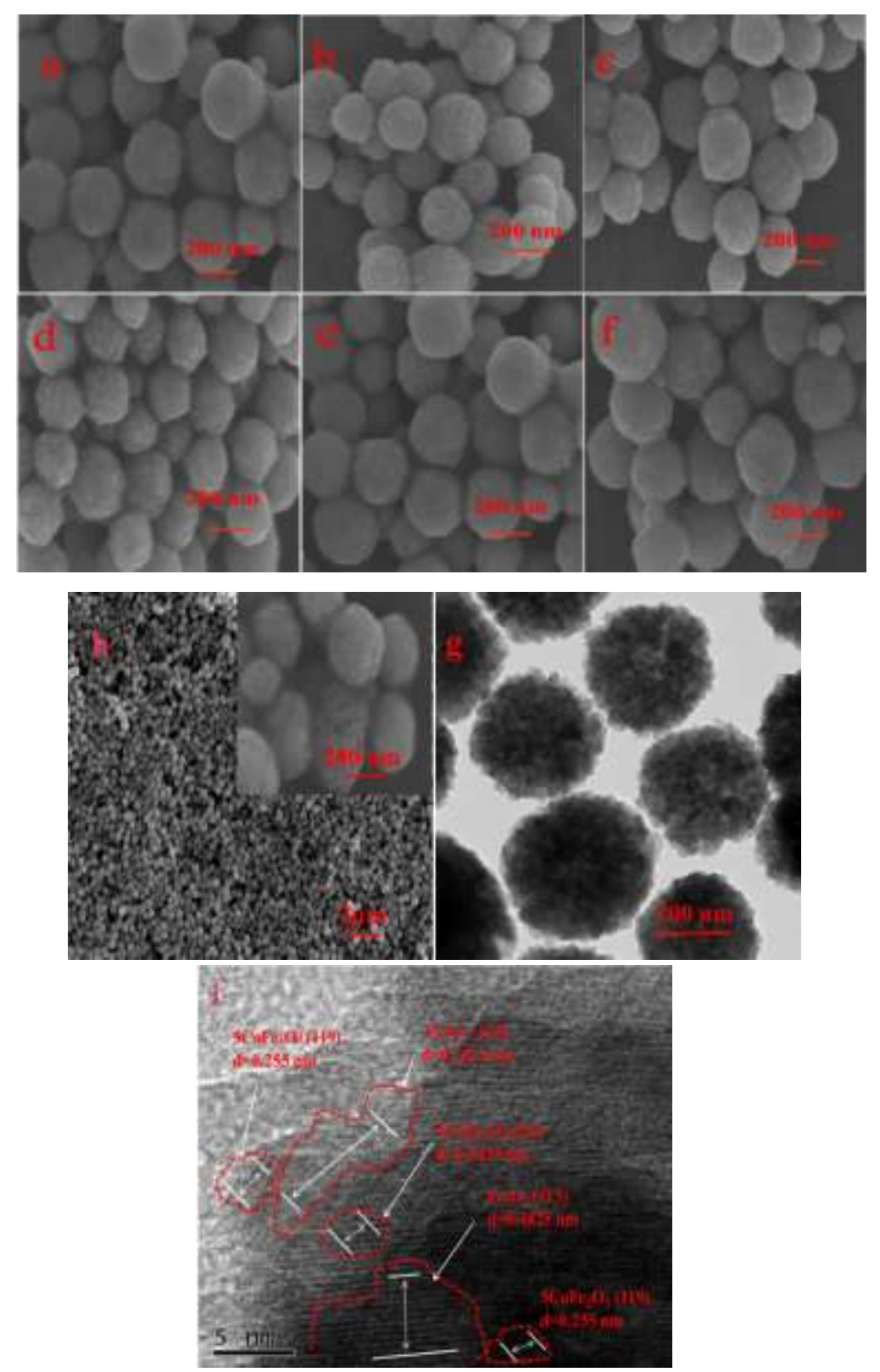

Figure 6. (a-f) SEM images of $\gamma-\mathrm{Fe}_{2} \mathrm{O}_{3}$ and 1-9Co-Fe, (h) low and high magnification images, (g-i) FESEM and HRTEM images of optimal catalyst 5Co-Fe, respectively

Figure 7

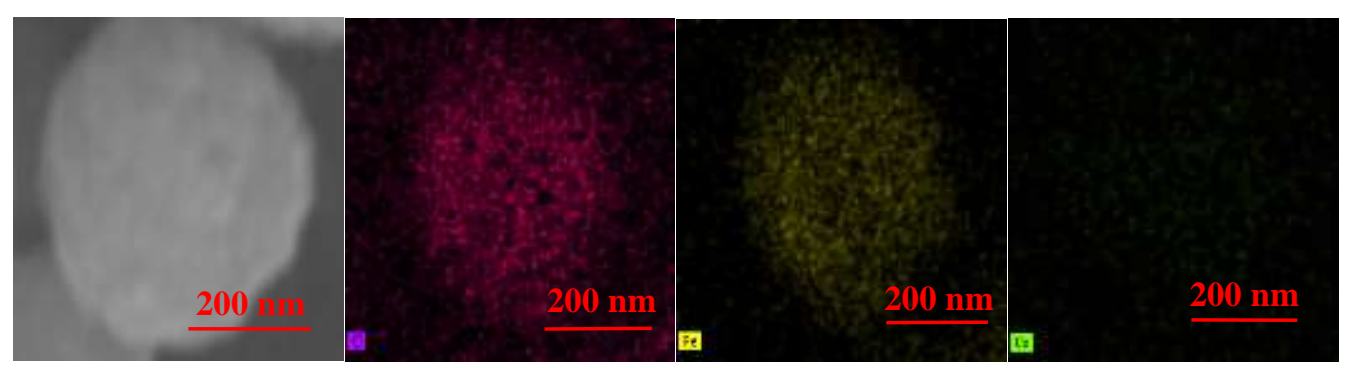

Figure 7. EDS element-mapping images of $\mathrm{O}$ (red), $\mathrm{Fe}$ (yellow), and $\mathrm{Co}$ (green) in 5 Co-Fe catalyst

Figure 8 

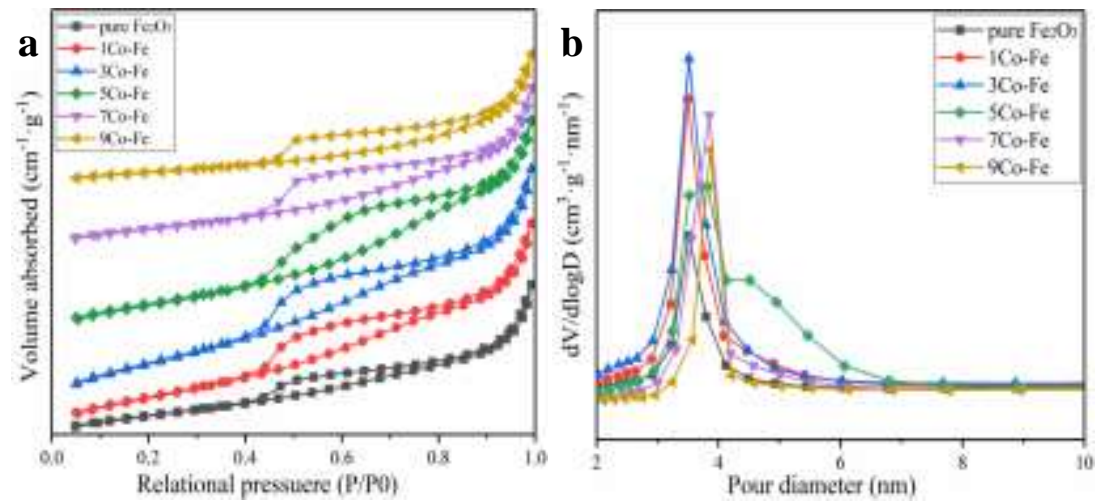

Figure 8. the results of (a) $\mathrm{N}_{2}$ adsorption-desorption isotherms and (b) aperture size distribution of the $\gamma$-xCoFe${ }_{2} \mathrm{O}_{3}$

\section{Figure 9}

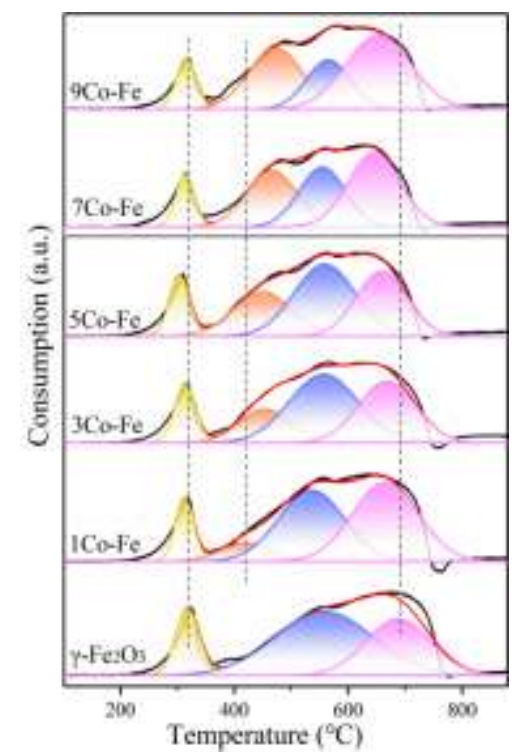

Figure 9. $\mathrm{H}_{2}$-TPR of $\gamma$-xCoFe ${ }_{2} \mathrm{O}_{3}$ catalysts

Figure 10

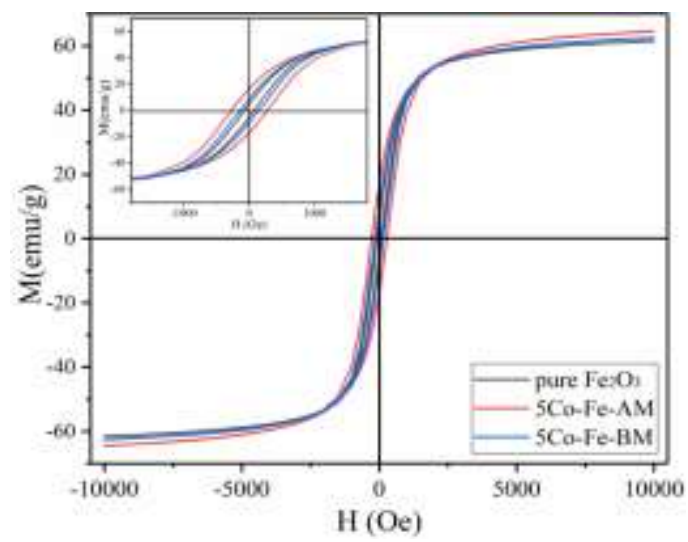

Figure 10. Samples' room temperature magnetization curves: pure $\gamma-\mathrm{Fe}_{2} \mathrm{O}_{3}$ (black), $\mathrm{BM}$ (blue) and $\mathrm{AM}$ (red) of the best active $5 \mathrm{Co}-\mathrm{Fe}$, respectively

\section{Figure 11}



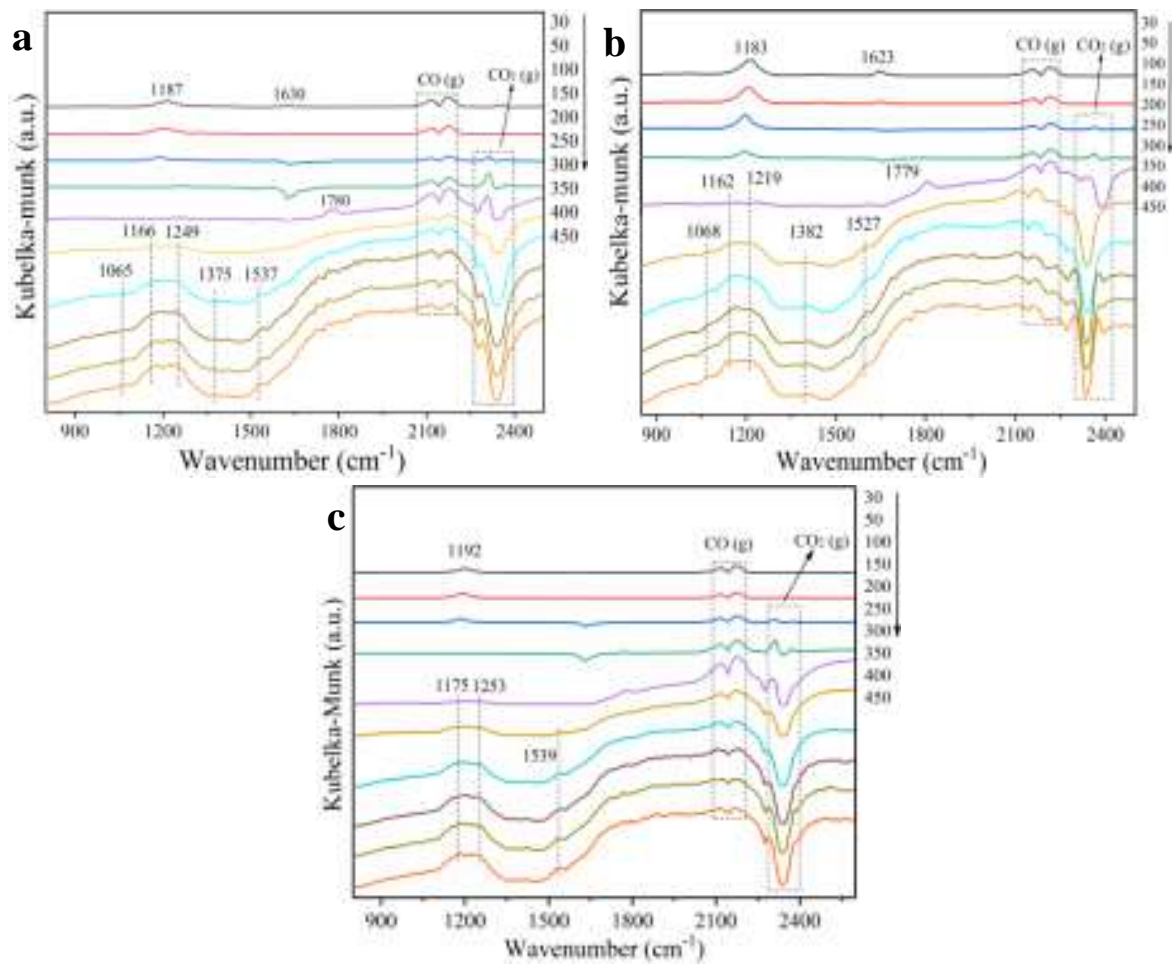

Figure 11. In situ DRIFTS results of CO atmosphere interaction with (a) 5Co-Fe-BM, (b) $5 \mathrm{Co}-\mathrm{Fe}-\mathrm{AM}$ and (c) pure $\gamma-\mathrm{Fe}_{2} \mathrm{O}_{3}$ catalysts $\left(30-450{ }^{\circ} \mathrm{C}\right)$

\section{Figure 12}
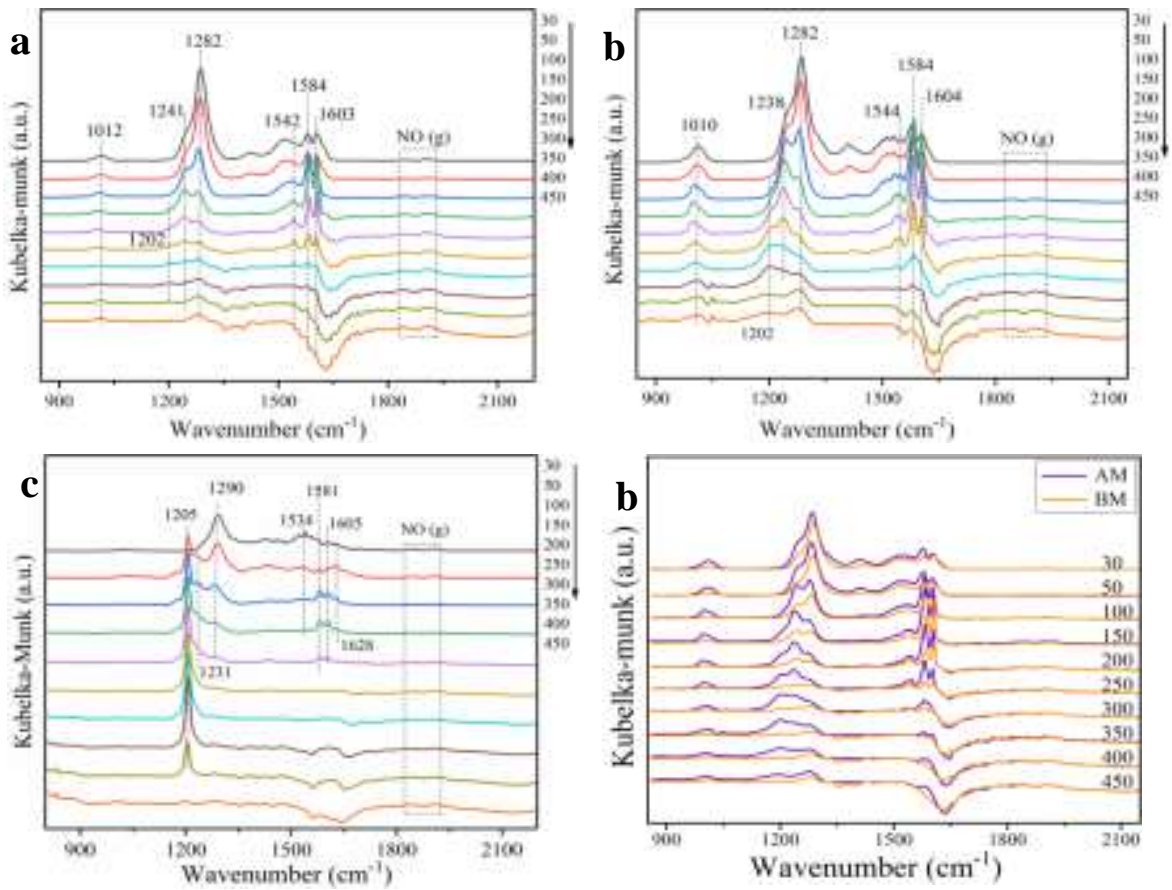

Figure 12. FT-IR results of NO atmosphere interaction with (a) 5Co-Fe-BM, (b) 5Co-Fe-AM (c) and pure $\gamma-\mathrm{Fe}_{2} \mathrm{O}_{3}$, (d) contrast of $5 \mathrm{Co}-\mathrm{Fe}-\mathrm{AM}$ and $5 \mathrm{Co}-\mathrm{Fe}-\mathrm{BM}$

\section{Figure 13}



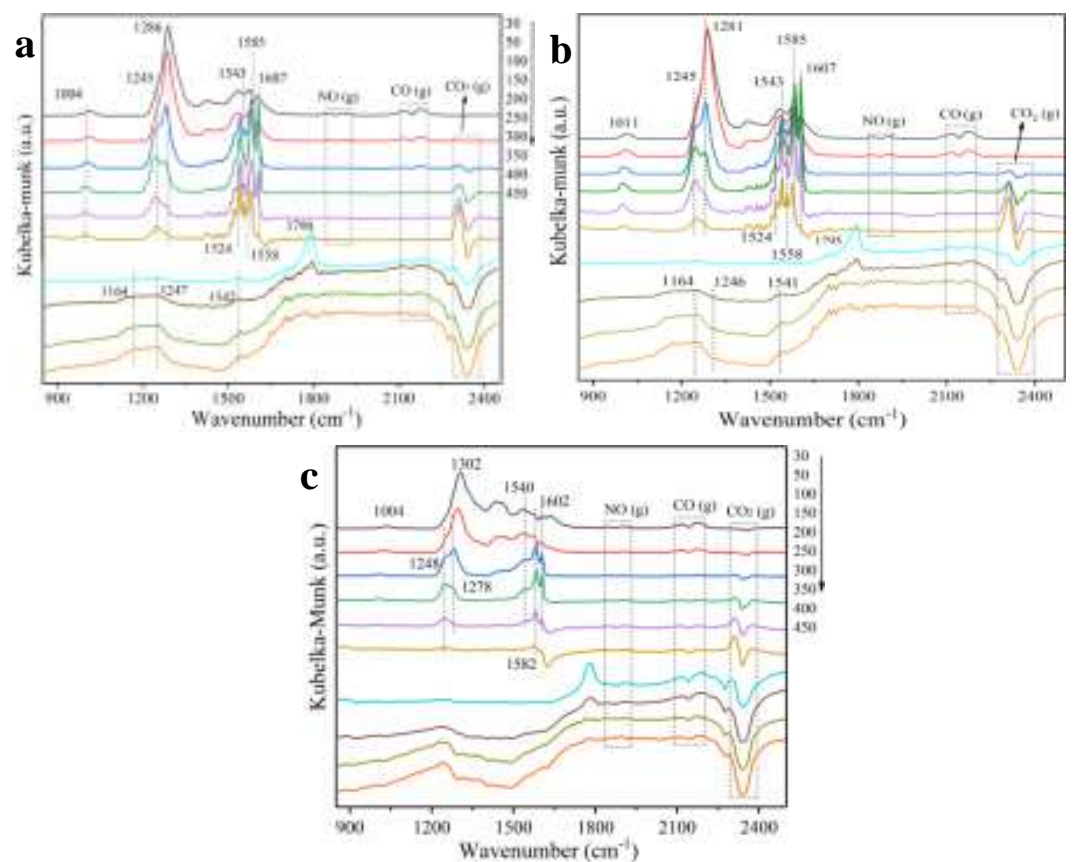

Figure 13. FT-IR results of (a) 5Co-Fe-BM, (b) 5Co-Fe-AM and (c) $\gamma-\mathrm{Fe}_{2} \mathrm{O}_{3}$ at each temperature in $\mathrm{NO}+\mathrm{CO}$ atmosphere, respectively

\section{Figure 14}

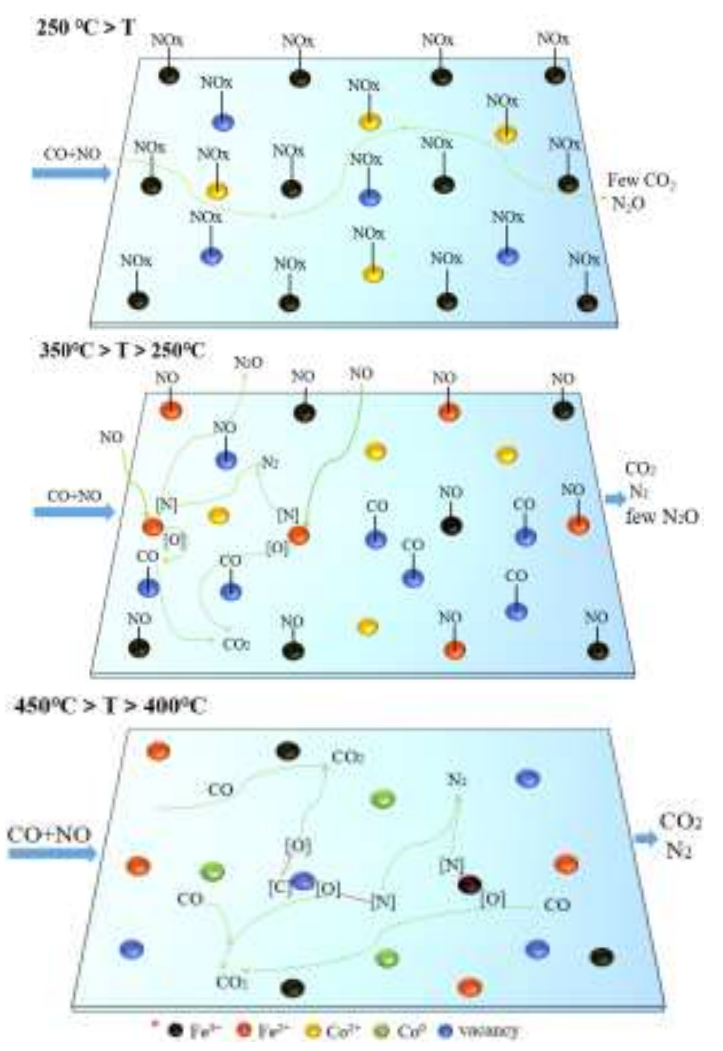

Figure. 14 schematic diagram of a possible reaction mechanism of CO-SCR on $5 \mathrm{Co}-\mathrm{Fe}$ catalyst 